\title{
Comparison of emissions inventories of anthropogenic air pollutants and greenhouse gases in China
}

\author{
Eri Saikawa ${ }^{1,2}$, Hankyul Kim ${ }^{2}$, Min Zhong ${ }^{1}$, Alexander Avramov ${ }^{1}$, Yu Zhao ${ }^{3}$, Greet Janssens-Maenhout ${ }^{4}$, \\ Jun-ichi Kurokawa ${ }^{5}$, Zbigniew Klimont ${ }^{6}$, Fabian Wagner ${ }^{6,7}$, Vaishali Naik ${ }^{8}$, Larry W. Horowitz ${ }^{8}$, and Qiang Zhang $^{9}$ \\ ${ }^{1}$ Department of Environmental Sciences, Emory University, Atlanta, GA, USA \\ ${ }^{2}$ Rollins School of Public Health, Emory University, Atlanta, GA, USA \\ ${ }^{3}$ School of the Environment, Nanjing University, Nanjing, China \\ ${ }^{4}$ European Commission, Joint Research Centre, Directorate of Energy, Transport and Climate, Via Fermi, 2749, \\ 21027 Ispra (VA), Italy \\ ${ }^{5}$ Asia Center for Air Pollution Research, 1182 Sowa, Nishi-ku, Niigata, Niigata, 950-2144, Japan \\ ${ }^{6}$ International Institute for Applied Systems Analysis, Laxenburg, Austria \\ ${ }^{7}$ Andlinger Center for Energy and the Environment, Princeton University, Princeton, NJ, USA \\ ${ }^{8}$ NOAA Geophysical Fluid Dynamics Laboratory, Princeton, NJ, USA \\ ${ }^{9}$ Center for Earth System Science, Tsinghua University, Beijing, China
}

Correspondence to: Eri Saikawa (eri.saikawa@emory.edu)

Received: 5 October 2016 - Discussion started: 27 October 2016

Revised: 31 March 2017 - Accepted: 31 March 2017 - Published: 30 May 2017

\begin{abstract}
Anthropogenic air pollutant emissions have been increasing rapidly in China, leading to worsening air quality. Modelers use emissions inventories to represent the temporal and spatial distribution of these emissions needed to estimate their impacts on regional and global air quality. However, large uncertainties exist in emissions estimates. Thus, assessing differences in these inventories is essential for the better understanding of air pollution over China. We compare five different emissions inventories estimating emissions of carbon dioxide $\left(\mathrm{CO}_{2}\right)$, carbon monoxide $(\mathrm{CO})$, nitrogen oxides $\left(\mathrm{NO}_{x}\right)$, sulfur dioxide $\left(\mathrm{SO}_{2}\right)$, and particulate matter with an aerodynamic diameter of $10 \mu \mathrm{m}$ or less $\left(\mathrm{PM}_{10}\right)$ from China. The emissions inventories analyzed in this paper include the Regional Emission inventory in ASia v2.1 (REAS), the Multi-resolution Emission Inventory for China (MEIC), the Emission Database for Global Atmospheric Research v4.2 (EDGAR), the inventory by Yu Zhao (ZHAO), and the Greenhouse Gas and Air Pollution Interactions and Synergies (GAINS). We focus on the period between 2000 and 2008, during which Chinese economic activities more than doubled. In addition to national totals, we also analyzed emissions from four source sectors (industry, transport,
\end{abstract}

power, and residential) and within seven regions in China (East, North, Northeast, Central, Southwest, Northwest, and South) and found that large disagreements exist among the five inventories at disaggregated levels. These disagreements lead to differences of $67 \mu \mathrm{g} \mathrm{m}^{-3}, 15 \mathrm{ppbv}$, and $470 \mathrm{ppbv}$ for monthly mean $\mathrm{PM}_{10}, \mathrm{O}_{3}$, and $\mathrm{CO}$, respectively, in modeled regional concentrations in China. We also find that all the inventory emissions estimates create a volatile organic compound (VOC)-limited environment and MEIC emissions lead to much lower $\mathrm{O}_{3}$ mixing ratio in East and Central China compared to the simulations using REAS and EDGAR estimates, due to their low VOC emissions. Our results illustrate that a better understanding of Chinese emissions at more disaggregated levels is essential for finding effective mitigation measures for reducing national and regional air pollution in China. 


\section{Introduction}

Obtaining accurate emissions estimates for air pollutant species is important in Asia, where five of the worst air quality countries in the world are located (Hsu et al., 2014). Emissions of ozone precursors, including nitrogen oxides $\left(\mathrm{NO}_{x}\right.$ $\equiv \mathrm{NO}+\mathrm{NO}_{2}$ ) and carbon monoxide (CO), affect tropospheric ozone $\left(\mathrm{O}_{3}\right)$ mixing ratio at local, regional, and intercontinental scales (Fiore et al., 2009; West et al., 2009). In addition to the emissions of primary particulate matter (PM), those of sulfur dioxide $\left(\mathrm{SO}_{2}\right)$ and $\mathrm{NO}_{x}$ also affect PM concentrations at local and regional scales. Both surface $\mathrm{O}_{3}$ and PM are linked to adverse health impacts (Dockery et al., 1993; Levy et al., 2001; Pope III et al., 2002), and $\mathrm{O}_{3}$ also affects agricultural crop yields (Heck et al., 1983; Krupa and Manning, 1988; Avnery et al., 2011).

One key country in need of accurate emissions estimates is China, the largest emitter and the biggest contributor to the uncertainty in the source and the magnitude of many of the air pollutant species. The difference in global $\mathrm{CO}, \mathrm{SO}_{2}$, and $\mathrm{NO}_{x}$ emissions estimates among inventories is 28,42 , and $17 \%$ in 2000, respectively (Granier et al., 2011). China's uncertainty is much larger for $\mathrm{CO}$ and $\mathrm{NO}_{x}$, and $90 \%$ of global $\mathrm{CO}_{2}$ emissions uncertainty stems from China (Andres et al., 2014). Energy consumption has been steadily increasing in China but, at the same time, the implementation of emissions control measures, including the flue-gas desulfurization (FGD) in coal-fired power plants, has led to rapid changes in emission factors in recent decades (Xu, 2011; Zhang et al., 2012; Kurokawa et al., 2013). Several emissions inventories have been developed in the past, either specifically for China or for Asia (Streets and Waldhoff, 2000; Streets et al., 2003; Zhao et al., 2008; Klimont et al., 2009; Lu et al., 2010; European Commission Joint Research Centre, JRC, 2011; Lei et al., 2011; Lu et al., 2011; Smith et al., 2011; Zhao et al., 2012; Kurokawa et al., 2013; Klimont et al., 2013), but none have assessed or compared emissions from different source sectors at more disaggregated scales than the national level.

The purpose of this study is to analyze the differences among the existing emissions inventory estimates for China's anthropogenic gaseous and aerosol emissions and how they affect air quality simulations. We analyze the emissions of carbon dioxide $\left(\mathrm{CO}_{2}\right)$, carbon monoxide (CO), sulfur dioxide $\left(\mathrm{SO}_{2}\right)$, nitrogen oxides $\left(\mathrm{NO}_{x}\right)$, non-methane volatile organic compounds (NMVOCs), and particulate matter with an aerodynamic diameter less than $10 \mu \mathrm{m}\left(\mathrm{PM}_{10}\right)$. We first evaluate the differences among inventories at the national level between years 2000 and 2008 for $\mathrm{CO}_{2}, \mathrm{CO}, \mathrm{SO}_{2}, \mathrm{NO}_{x}$, and $\mathrm{PM}_{10}$ and produce composite emissions estimates, using Monte Carlo samplings. Second, we focus on four source sectors (industry, transport, power, and residential) in seven regions of China (the East, North, Northeast, Central, Southwest, Northwest and South) for $\mathrm{CO}, \mathrm{SO}_{2}, \mathrm{NO}_{x}$, and $\mathrm{PM}_{10}$. Next, we analyze emissions estimates in the transport sector in more detail. By disaggregating emissions into these source sectors and regions, we aim to understand where the differences occur and how we can better constrain emissions. We also use a chemical transport model, the Weather Research and Forecasting model coupled with Chemistry (WRF-Chem), to assess how the different emissions estimates affect air quality modeling results.

The paper is organized as follows. Section 2 explains the emissions inventories that we have compared. Section 3 analyzes the differences in emissions inventories first at the national level and then in seven regions within China. Section 4 compares transport sector emissions in depth. Section 5 describes the impact of the emissions inventories on air quality simulations. Section 6 presents a summary of results and suggested future research.

\section{Emissions inventories}

In this study, we compare five existing emissions inventories at the national, regional, and source sector levels between years 2000 and 2008 (Table 1). The Regional Emission inventory in ASia version 2.1 (REAS) is a regional emissions inventory for most of the Asian countries, including East, Southeast, South, and Central Asia and the Asian part of Russia (Kurokawa et al., 2013). The Emission Database for Global Atmospheric Research version 4.2 (EDGAR) is a global emissions inventory and includes major air pollutants from combustion and non-combustion sources (European Commission Joint Research Centre, JRC, 2011). The Multi-resolution Emission Inventory for China (MEIC, http://meicmodel.org/) is an inventory developed at Tsinghua University, Beijing, China, and provides national emissions estimates for 2008 and 2010. A national emissions inventory for the 2000-2014 period was developed at Nanjing University (Zhao et al., 2008) and includes disaggregated information at the source sector and provincial levels for the year 2007. The Greenhouse Gas and Air Pollution Interactions and Synergies (GAINS, http://gains.iiasa.ac.at/models/ index.html) model is a framework for analyzing co-benefits of reduction strategies for air pollution and greenhouse gas sources globally, which provides estimates of emissions, including province-level emissions from China (Amann et al., 2011). These five emissions inventories were developed using a similar methodology, where emissions were calculated as the product of activity data, such as fuel consumption or industrial production, emission factors of combustion or production technology, and penetration rate and emission reduction efficiency of emission controls (Zhao et al., 2014). Table 2 shows how emissions in each of the inventories are aggregated to the four primary source sectors (industry, transport, power, and residential) that we analyze in this paper. They were grouped in this way to be able to compare at the four source sector levels among the inventories, as this is how some of the inventories (i.e., MEIC) are structured. Here we explain each of the emissions inventories in more detail. 
Table 1. Description of emissions inventories used for this study.

\begin{tabular}{|c|c|c|c|c|c|c|}
\hline & Years & Source sectors & Species & $\begin{array}{l}\text { Horizontal } \\
\text { resolution }\end{array}$ & Coverage & Reference \\
\hline REAS & 2000-2008 & $\begin{array}{l}\text { power plants, combustible and non- } \\
\text { combustible sources in industry, on-road and } \\
\text { off-road sources in transport, residential, } \\
\text { agricultural, and other anthropogenic sources }\end{array}$ & $\begin{array}{l}\mathrm{CO}_{2}, \mathrm{SO}_{2}, \mathrm{CO} \\
\mathrm{PM}_{10}, \mathrm{PM}_{2.5}, \mathrm{BC} \\
\mathrm{OC}, \mathrm{NO}_{x}, \mathrm{NH}_{3} \\
\mathrm{NMVOC}, \mathrm{CH}_{4}, \mathrm{~N}_{2} \mathrm{O}\end{array}$ & $0.25^{\circ} \times 0.25^{\circ}$ & $\begin{array}{l}\text { East, Southeast, } \\
\text { South \& Central } \\
\text { Asia, Asian part of } \\
\text { Russia }\end{array}$ & Kurokawa et al. (2013) \\
\hline EDGAR & 1970-2008 & $\begin{array}{l}\text { energy, industrial processes, product use, } \\
\text { on-road and off-road sources in transport, agriculture, } \\
\text { large-scale biomass burning, and other anthropogenic sources }\end{array}$ & $\begin{array}{l}\mathrm{CO}_{2}, \mathrm{SO}_{2}, \mathrm{CO} \\
\mathrm{PM}_{10}, \mathrm{NO}_{x}, \mathrm{NH}_{3} \\
\mathrm{NMVOC}, \mathrm{CH}_{4}, \mathrm{~N}_{2} \mathrm{O} \\
\mathrm{HFCs}, \mathrm{SF}_{6}, \mathrm{NF}_{3}\end{array}$ & $0.1^{\circ} \times 0.1^{\circ}$ & Global & EC-JRC/PBL (2011) \\
\hline MEIC & 2008,2010 & $\begin{array}{l}\text { power, industry, on-road and off-road sources in transport, } \\
\text { residential and agricultural sources }\end{array}$ & $\begin{array}{l}\mathrm{CO}_{2}, \mathrm{SO}_{2}, \mathrm{CO}, \\
\mathrm{PM}_{10}, \mathrm{NO}_{x}, \mathrm{NMVOC}\end{array}$ & $0.1^{\circ} \times 0.1^{\circ}$ & China & www.meicmodel.org \\
\hline ZHAO & 2000-2014 & $\begin{array}{l}\text { power, combustible and non- } \\
\text { combustible sources in industry, on-road and } \\
\text { off-road sources in transport, and residential }\end{array}$ & $\begin{array}{l}\mathrm{CO}_{2}, \mathrm{SO}_{2}, \mathrm{CO} \\
\mathrm{TSP}, \mathrm{PM}_{10}, \mathrm{PM}_{2.5} \\
\mathrm{BC}, \mathrm{OC}, \mathrm{NO}_{x}, \mathrm{Hg}\end{array}$ & NA & China & $\begin{array}{l}\text { Zhao et al. (2013b) } \\
\text { Zhao et al. (2015) } \\
\text { Cui et al. (2015) } \\
\text { Xia et al. (2016) }\end{array}$ \\
\hline GAINS & $\begin{array}{l}1990-2030 \\
\text { (5-year increment, } \\
\text { projection starting } \\
\text { in 2015) }\end{array}$ & $\begin{array}{l}\text { energy, industrial combustion and } \\
\text { processes, on-road and off-road sources in transport, } \\
\text { residential, and agriculture }\end{array}$ & $\begin{array}{l}\mathrm{CO}_{2}, \mathrm{SO}_{2}, \mathrm{CO}, \\
\mathrm{TSP}, \mathrm{PM}_{10}, \mathrm{PM}_{2.5}, \\
\mathrm{PM}_{1}, \mathrm{BC}, \mathrm{OC}, \mathrm{NO}_{x}, \\
\mathrm{NH}_{3}, \text { VOC, } \mathrm{CH}_{4}, \\
\mathrm{~N}_{2} \mathrm{O}, \mathrm{F} \text { gases }\end{array}$ & $0.5^{\circ} \times 0.5^{\circ}$ & Global & $\begin{array}{l}\text { Amann et al. (2011) } \\
\text { Klimont et al. (2017) } \\
\text { Klimont et al. (2017) }\end{array}$ \\
\hline
\end{tabular}

$\mathrm{NA}=$ not available

\section{$2.1 \quad$ REAS}

REAS was developed collaboratively between the National Institute for Environmental Studies and Asia Center for Air Pollution Research, Japan (Kurokawa et al., 2013). The inventory comprises emissions data from 30 Asian countries and regions, including China, divided into 33 sub-regions (22 provinces, five autonomous regions, four municipalities, and two special administrative regions), between years 2000 and 2008 at a $0.25^{\circ}$ longitude $\times 0.25^{\circ}$ latitude horizontal resolution. A previous version of REAS spanned a longer time period and included projections of emissions (Ohara et al., 2007), but v2.1 is based on updated activity data and parameters. The emissions sources provided are power plants, combustible and non-combustible sources in industry, on-road and off-road sources in transport, and residential and others such as agricultural activities and evaporative sources. Important proxies for gridding include rural, urban, and total populations, as well as road networks.

\subsection{EDGAR}

EDGAR was developed by the Joint Research Centre of the European Commission, in collaboration with the Netherlands Environmental Assessment Agency (European Commission Joint Research Centre, JRC, 2011). This database incorporated experiences of the dataset EDGAR v3.2 FT2000 from Olivier et al. (2001). EDGAR is a gridded emissions inventory of greenhouse gases, air pollutants, and aerosols that spans $1970-2008$ at a $0.1^{\circ}$ longitude $\times 0.1^{\circ}$ latitude horizontal resolution. The source sectors provided are energy, industrial processes, product use, agriculture, waste, and other anthropogenic sources. Country emissions are compiled based on the International Energy Agency (IEA) energy statistics. Emission factors are taken from the EMEP/EEA air pollu- tant emission inventory guidebook (European Environment Agency, 2013) and other scientific literature. Gridding of national total emissions is done using several types of proxy data (population, road, power plants, animals, and crop) as described in Janssens-Maenhout et al. (2013).

\subsection{MEIC}

MEIC is an inventory developed at Tsinghua University, Beijing, China, and provides source sector information for the 31 Chinese sub-regions (all those included in the REAS, except the two special administrative regions: Hong Kong and Macau) for 2008 and 2010 (Li et al., 2014; Zheng et al., 2014; Li et al., 2017; Liu et al., 2015). The MEIC model has a flexible spatial and sectoral resolution and allows for gridding of the emission product into a user-specific grid including $0.25^{\circ}$ longitude $\times 0.25^{\circ}$ latitude horizontal resolution as well as coarser grids. The emissions source sectors provided are power plants, industry, transport, residential, and agricultural sources. Important proxy data for gridding of emissions includes population, roads, and power plants.

\subsection{ZHAO}

The inventory made at Nanjing University is a national inventory that estimates source sector emissions from all the 31 Chinese sub-regions, the same as MEIC (Y. Zhao et al., 2013; Zhao et al., 2015; Cui et al., 2015; Xia et al., 2016). The inventory includes the national-level data for 2000-2008, and we use the available disaggregated emissions estimates for 2007 for comparison. The sectors provided are industry (including cement, iron and steel, other industrial combustion, and other industrial processes), power, transport (including on-road and off-road), and residential. This inventory does not provide gridded emissions. 


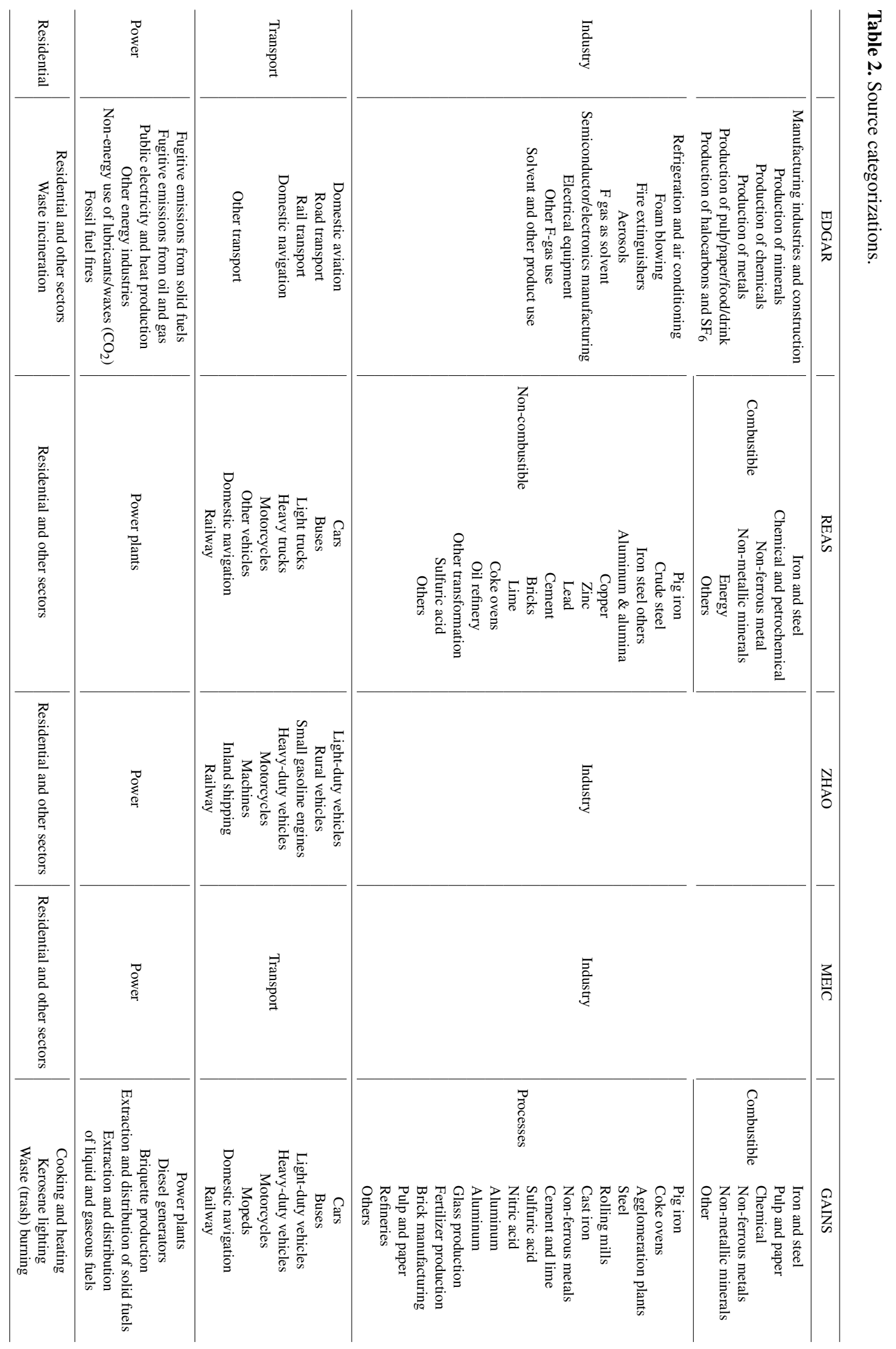




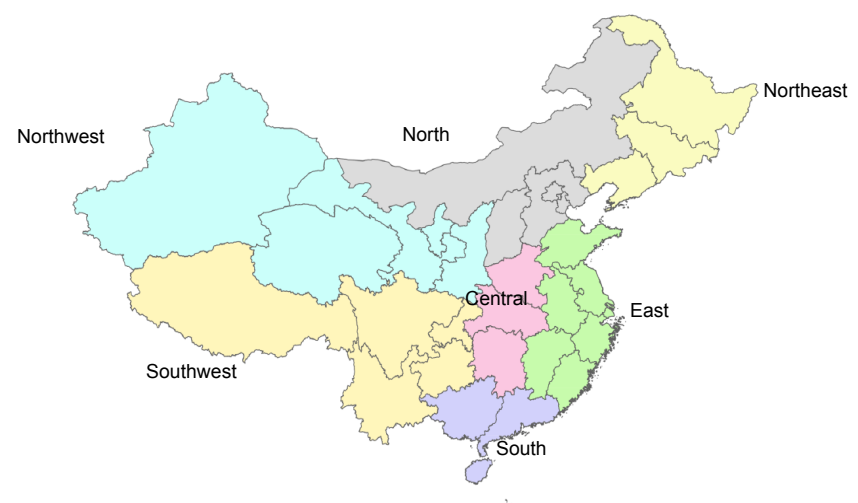

Figure 1. Seven regions in China used for analysis in this paper.

\subsection{GAINS}

The GAINS model was developed at the International Institute for Applied Systems Analysis and estimates global emissions, including those for the 31 sub-regions in China, as in MEIC and ZHAO, as well as Hong Kong and Macau, as in REAS (Amann et al., 2008; Klimont et al., 2009). The GAINS model calculates emissions estimates in 5-year intervals from 1990 to 2050, with the projection starting in year 2015. It has a large number of source sectors including energy, domestic, industrial combustion and processes, road and non-road transport, and agriculture, for which activities originate from international and national statistics. It provides output in various formats and spatial resolution, including $0.5^{\circ}$ latitude $\times 0.5^{\circ}$ longitude horizontal grid. For this study, we use estimates from energy, domestic, transport, and industry sectors for the years 2000 and 2005, using the global dataset developed within the European Union project ECLIPSE (version V5a, http://www.iiasa.ac.at/web/home/ research/researchPrograms/air/Global_emissions.html)

(Klimont et al., 2016). Sectoral proxies used in Representative Concentration Pathways and Global Energy Assessment (GEA, 2012), as well as population and selected industrial plant locations, are used as important proxies for gridding (Klimont et al., 2016).

\section{National and regional comparisons}

To better understand the differences among anthropogenic emissions estimates of four air pollutant species, we first analyzed differences in national total emissions estimates between years 2000 and 2008. For each of the species, we further compared these estimates in seven different regions (Fig. 1) for four source sectors separately. In the following sections, we first describe the differences at the national level and then at the regional level for each species.

\subsection{National-level comparisons}

Figure 2 illustrates China's national total emissions for the four air pollutant species of our interest $\left(\mathrm{CO}, \mathrm{SO}_{2}, \mathrm{NO}_{x}\right.$, and $\mathrm{PM}_{10}$ ) as well as $\mathrm{CO}_{2}$ estimated by REAS, EDGAR, MEIC, ZHAO, and GAINS, between 2000 and 2008, along with other published study estimates. We also used one million Monte Carlo samples from all emissions inventories, sector by sector, to create a composite emissions estimate for each species. For the inventories that provided a standard deviation or uncertainty, we used the information and assumed either a normal or log-normal distribution based on the information provided. If such information was not available, we used the relative uncertainty percentage provided by REAS for a sector for each species to estimate standard deviation and assumed normal distribution.

We find the largest difference, ranging from $65-94 \mathrm{Tg} \mathrm{yr}^{-1}$ (87-106\%), between REAS and EDGAR emissions estimates for total CO in China, with REAS exceeding EDGAR throughout the 2000-2008 time period (Fig. 2). We further find that the major sectors leading to the differences are industry and transport (Fig. 3). Indeed, between REAS and EDGAR, $39 \%$ of the difference in national total $\mathrm{CO}$ emissions stems from the industry sector in 2000. By 2008, the emissions difference in the industry sector contributes $51 \%$ of the total emissions difference for $\mathrm{CO}$ emissions in China.

What is the cause of this large difference within the industry sector? Coal combustion plays a large role in $\mathrm{CO}$ emissions from this sector in the REAS estimate, and $98.6 \%$ of the combustible industrial emissions are due to coal in 2008. The comparison of fuel use statistics among REAS, EDGAR, and GAINS for 2000 (Fig. 4) and net emission factors per sector among REAS, EDGAR, GAINS, and MEIC (Fig. 5) is useful in understanding the reason behind the differences. Coal use in industry between REAS and EDGAR shows similar values, but there is a large difference in emission factors for industrial $\mathrm{CO}$ between REAS $(2.2 \mathrm{t} \mathrm{CO} / \mathrm{TJ})$ and EDGAR (1.1 t CO/TJ). Because emission factors are related to each technology type, penetration of the technology, uncontrolled emission factor, and the emission reduction efficiency of each technology type, these factors all contribute to differences. Obtaining estimates for $\mathrm{CO}$ is particularly difficult because of the many technology types that exist for emissions reduction. For the transport sector, estimated emissions by EDGAR are still lower than those of REAS (Fig. 3), even with its similar fuel use (Fig. 4), most likely because the modeling of super-emitters has been omitted in EDGAR.

The smallest CO source sector is power, and it has the smallest difference among the inventories. Power emissions only contribute to $1.9,3.1,1.1$, and $0.8 \%$ of the national emissions in REAS, EDGAR, MEIC, and ZHAO, respectively, in 2008 for the former three and in 2007 for ZHAO. GAINS estimates $1.0 \%$ of its national emissions comes from power in 2005 . REAS estimates a $2.3 \mathrm{Tg}(159 \%)$ increase in CO emissions from the power sector between 2000 and 2008, 

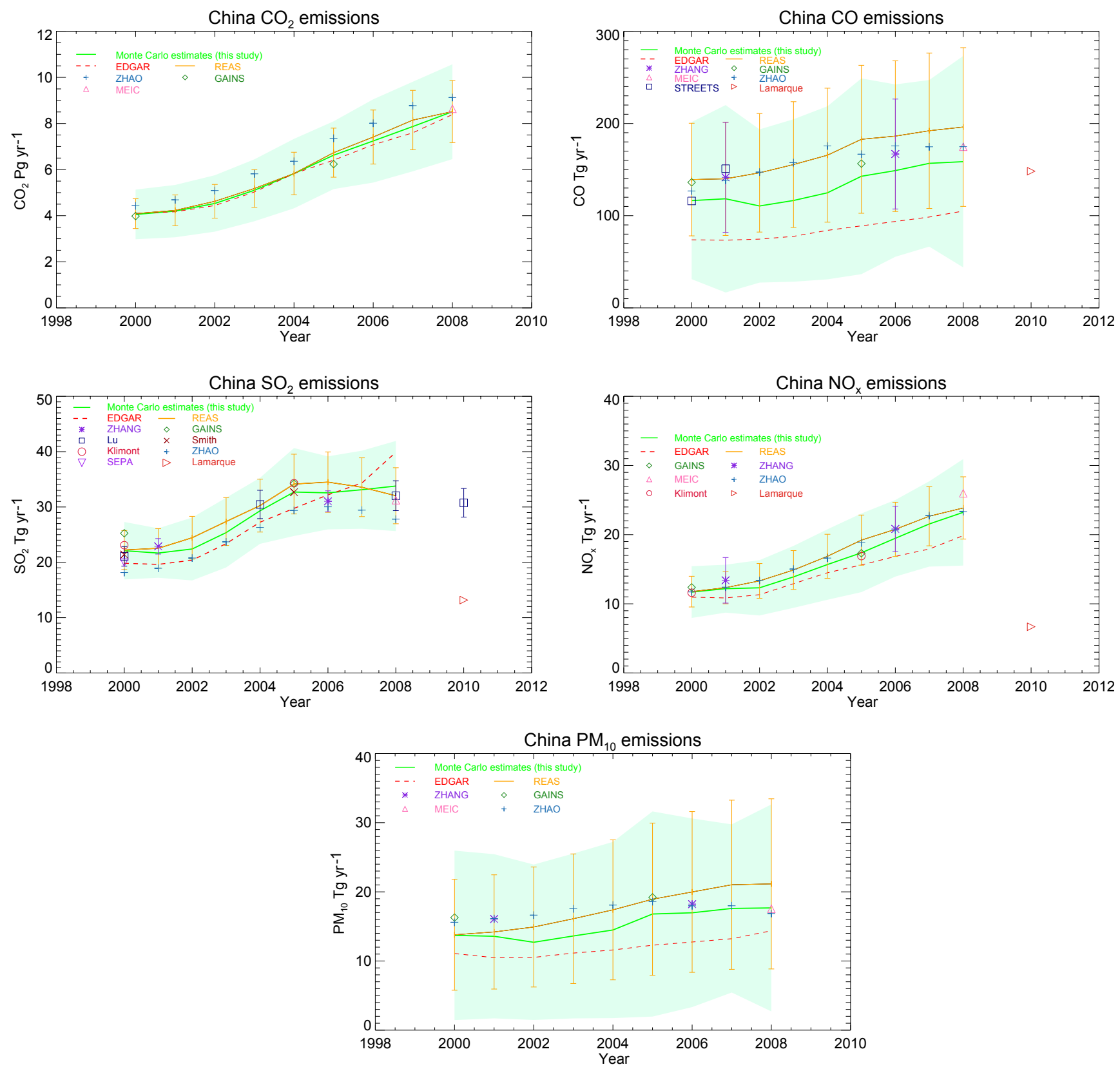

Figure 2. National total emissions estimates for $\mathrm{CO}_{2}, \mathrm{CO}, \mathrm{SO}_{2}, \mathrm{NO}_{x}$, and $\mathrm{PM}_{10}$ estimated by REAS, EDGAR, MEIC, ZHAO, and GAINS between 2000 and 2008, along with other existing emissions inventory estimates. Other estimates include Zhang et al. (2009), Streets et al. (2003), Lamarque et al. (2010), Lu et al. (2011), Smith et al. (2009), Klimont et al. (2013), and State Environmental Protection Administration SEPA (2000). Our Monte Carlo estimates are also included with 1 standard deviation shown as a shade.

while EDGAR only estimates a $0.43 \mathrm{Tg}(15 \%)$ increase in the same time period. At the national level, the difference in $\mathrm{CO}$ emissions from the power sector between REAS and EDGAR decreased from 50 to $13 \%$ between the same period (2000-2008).

The difference for $\mathrm{PM}_{10}$ between REAS and EDGAR is also not insignificant and ranges between 2.7 and $7.8 \mathrm{Tg} \mathrm{yr}^{-1}$ (25 and $59 \%$ ) over time (Fig. 2). Similar to CO, REAS esti- mates the highest and EDGAR estimates the lowest national $\mathrm{PM}_{10}$ emissions. As shown in Fig. 3, the major differences arise mainly from the industry sector, where EDGAR emissions show significantly lower estimates compared to those of REAS and all the others. The opposite is the case for power sector emissions, and EDGAR emissions are double those of REAS and others. For PM 10 , EDGAR estimates lower fuel use for coal and oil in industry than REAS and 

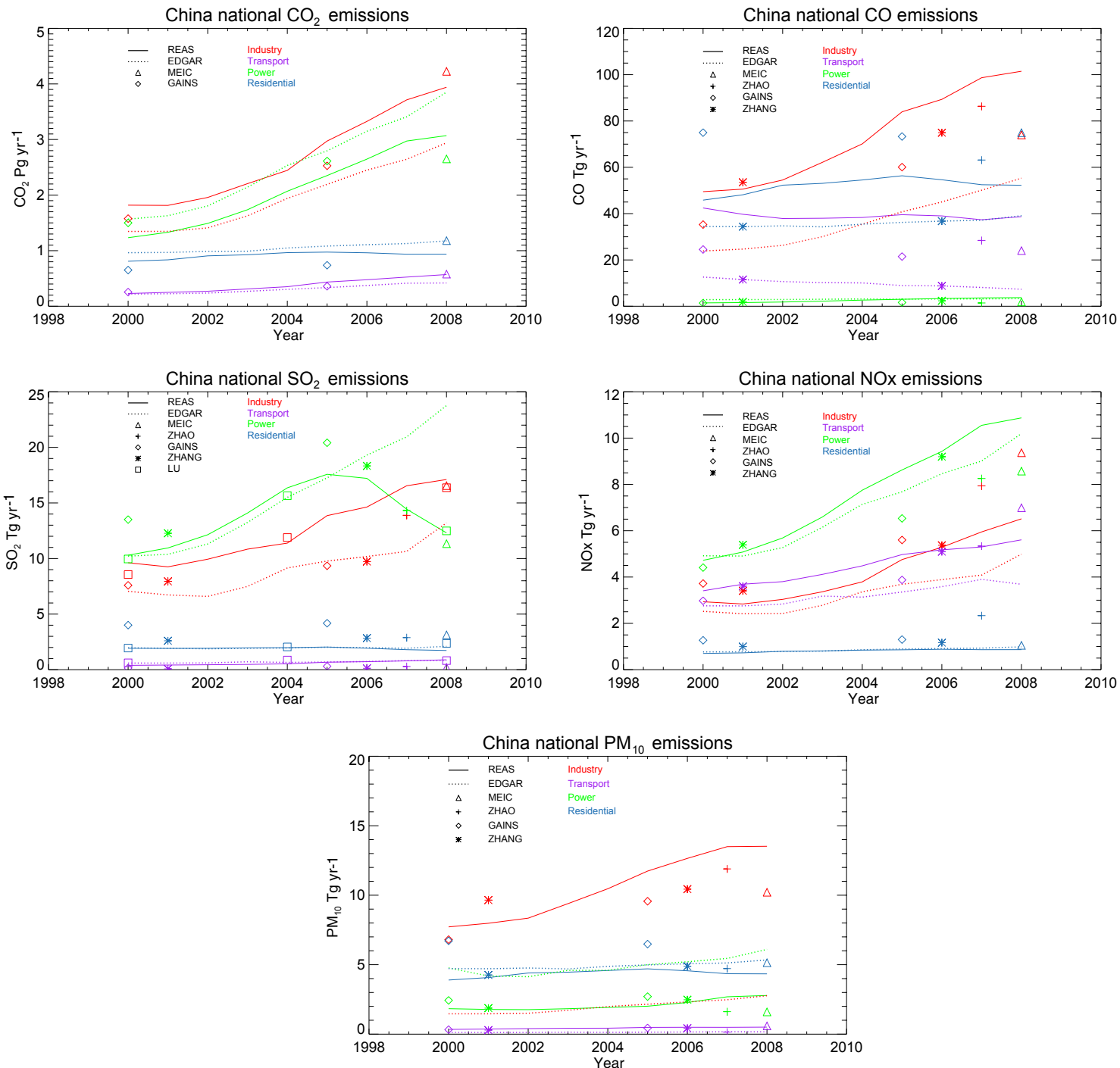

Figure 3. National emissions estimates for $\mathrm{CO}_{2}, \mathrm{CO}, \mathrm{SO}_{2}, \mathrm{NO}_{x}$, and $\mathrm{PM}_{10}$ by source sector estimated by REAS, EDGAR, MEIC, ZHAO, and GAINS between 2000 and 2008. Zhang et al. (2009) and Lu et al. (2011) estimates are also included where possible.

2000 fuel use

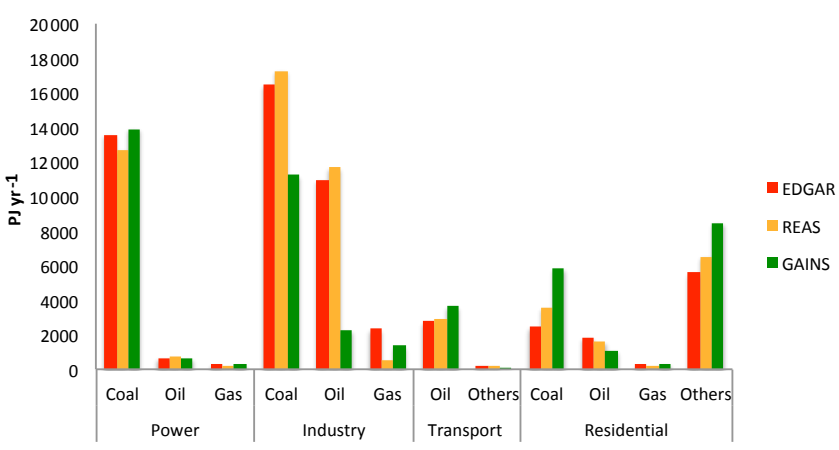

Figure 4. Total fuel use estimates by REAS, EDGAR, and GAINS for the four source sectors in 2000 . higher fuel use for coal and gas in power sector than REAS (Fig. 4). The net emission factor for $\mathrm{PM}_{10}$ in industry is also lower for EDGAR than REAS, and the opposite is the case for power (Fig. 5). EDGAR thus estimates lower emissions for industry, while estimating higher emissions than REAS for the power sector (Fig. 3). The large difference in industrial $\mathrm{PM}_{10}$ emissions may also be due to differences in removal efficiency of a certain technology embedded in emission calculations among inventories.

The power emissions for $\mathrm{NO}_{x}$ dominate the national total for REAS, EDGAR, and Zhang et al. (2009) (Fig. 3). A total of $10.9 \mathrm{Tg} \mathrm{yr}^{-1}(46 \%)$ and $10.2 \mathrm{Tg} \mathrm{yr}^{-1}(51 \%)$ of the national $\mathrm{NO}_{x}$ emissions are estimated to come from the power sector in REAS and EDGAR, respectively, in 2008. Additionally, $9.2 \mathrm{Tg} \mathrm{yr}^{-1}(44 \%)$ is estimated to come from the power sector in 2006 in the INTEX-B inventory by Zhang 
CO

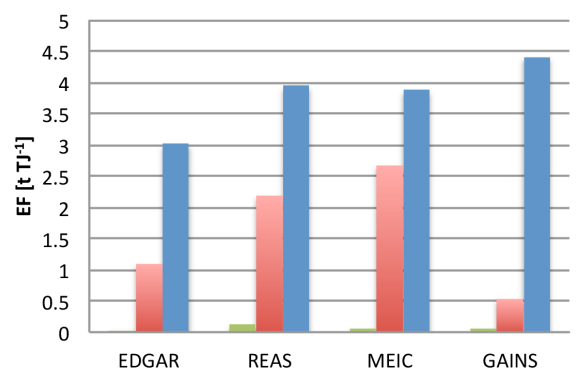

NOx

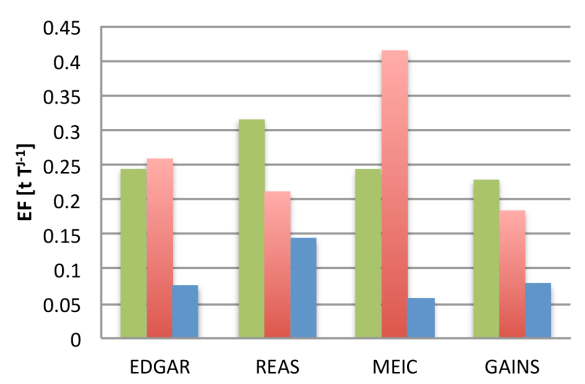

$\mathrm{SO}_{2}$

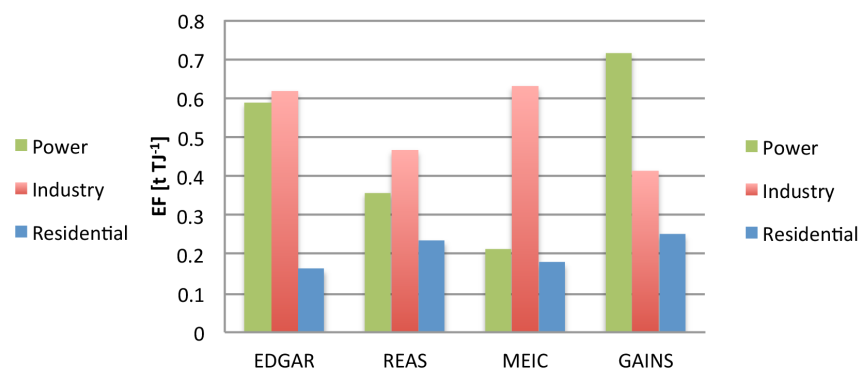

$\mathrm{PM}_{10}$
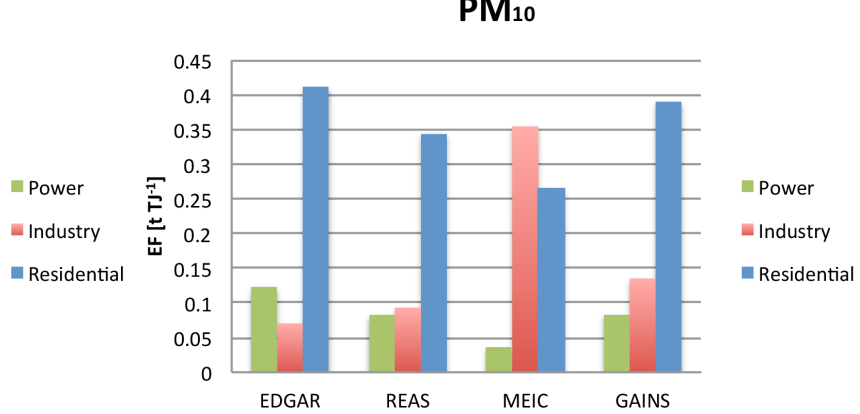

Figure 5. Net emission factors for $\mathrm{CO}, \mathrm{SO}_{2}, \mathrm{NO}_{x}$, and $\mathrm{PM}_{10}$ used among REAS and EDGAR for 2008, MEIC for 2010, and GAINS for 2005 for the three source sectors.

et al. (2009). Streets et al. (2003) estimated power to be the dominant source sector, contributing $4.4 \mathrm{Tg} \mathrm{yr}^{-1}(39 \%$ of $\mathrm{NO}_{x}$ emissions) in 2000 , followed by $2.8 \mathrm{Tg} \mathrm{yr}^{-1}$ each (equal $25 \%$ contribution) from industry and transport. The national emissions inventories, however, do not show power sector emissions dominating for $\mathrm{NO}_{x}$. For MEIC, industrial emissions are estimated to be slightly higher than those from the power sector. For ZHAO, the two sources are similar in magnitude. A total of $33 \%(36 \%)$ and $35 \%$ (35\%) of the total emissions equalling $8.6 \mathrm{Tg} \mathrm{yr}^{-1}\left(9.4 \mathrm{Tg} \mathrm{yr}^{-1}\right)$ and 8.3 $\mathrm{Tg} \mathrm{yr}^{-1}\left(7.9 \mathrm{Tg} \mathrm{yr}^{-1}\right)$ are estimated to come from the power (industry) sector in the two national inventories of MEIC in 2008 and ZHAO in 2007, respectively. One of the possible reasons for this is due to the difference in the net emission factors among emission inventories (Fig. 5). MEIC estimates much higher emission factors for $\mathrm{NO}_{x}$ emissions from the industry sector than from power, unlike other inventories that estimate the opposite (REAS and GAINS) or are fairly close to each other (EDGAR).

The differences for the other species are smaller, although it is clear that Lamarque et al. (2010) estimates much lower emissions for both $\mathrm{NO}_{x}$ and $\mathrm{SO}_{2}$, compared to others (Fig. 2). The range of the absolute difference between REAS and EDGAR for $\mathrm{CO}_{2}$ and $\mathrm{SO}_{2}$ are 4.25-553 $\mathrm{Tg} \mathrm{yr}^{-1}$ and $0.75-7.9 \mathrm{Gg} \mathrm{yr}^{-1}$, respectively, between 2000 and 2008. MEIC and ZHAO emissions estimates fall between the REAS and EDGAR estimates most of the time, although they are closer to the REAS estimates, which are higher than those of EDGAR, for most species. GAINS estimates sometimes do not fall between the REAS and EDGAR estimates, but the differences are still small. The timing of the $\mathrm{SO}_{2}$ emissions reduction in 2007 in REAS coincides with what is reported in Zhang et al. (2009), Klimont et al. (2009), and Lu et al. (2011).

\subsection{Regional-level comparisons}

When we compare emissions in the seven regions within China (East, North, Northeast, Central, Southwest, Northwest, and South, as shown in Fig. 1), we find larger differences than at the national level for almost all species (Figs. 69). We compare in detail the differences among emissions inventories for each species per region and for each source sector below.

\subsubsection{Carbon monoxide, CO}

Atmospheric CO is mainly a result of incomplete combustion of fossil fuels and biofuels, and exposure to ambient CO is harmful to human health (Aronow and Isbell, 1973; Stern et al., 1988; Allred et al., 1989; Morris et al., 1995). $\mathrm{CO}$ emissions are also important precursors to the formation of tropospheric $\mathrm{O}_{3}$, which also has harmful human health impacts, including increased asthma exacerbations, decreased pulmonary function, and increased mortality (Schwartz et al., 1994; Mudway and Kelly, 2000; Levy et al., 2005). Because of the existence of diverse emissions sources with various emissions control technologies in China, it has been a chal- 

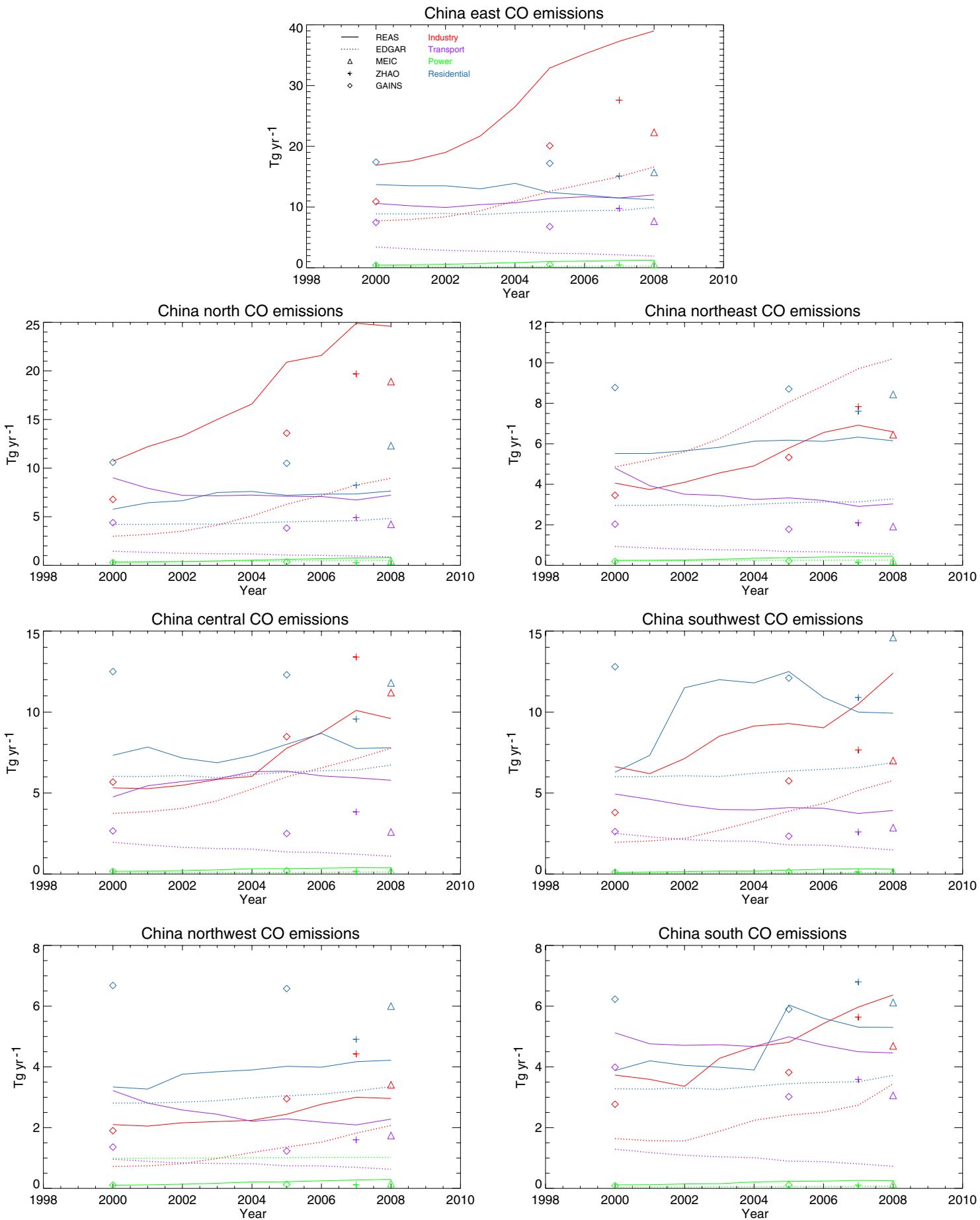

Figure 6. Regional total emissions for CO for four different source sectors (industry, transport, power, and residential) estimated by REAS, EDGAR, MEIC, ZHAO, and GAINS between 2000 and 2008.

lenge to estimate $\mathrm{CO}$ emissions accurately, using a bottomup methodology with emission factors and activity levels (Streets et al., 2006). This explains why we see the largest difference in $\mathrm{CO}$ emissions estimates at the national level compared in Fig. 2 to all other species.
Figure 6 shows the seven regional $\mathrm{CO}$ emissions estimates from each source sector. For $\mathrm{CO}$ emissions, industry is the only source sector that shows a steep increase over time in all regions for REAS and EDGAR estimates, especially between 2002 and 2008. GAINS also shows an increase between 2000 and 2005. Due to the rapid increase in its emis- 

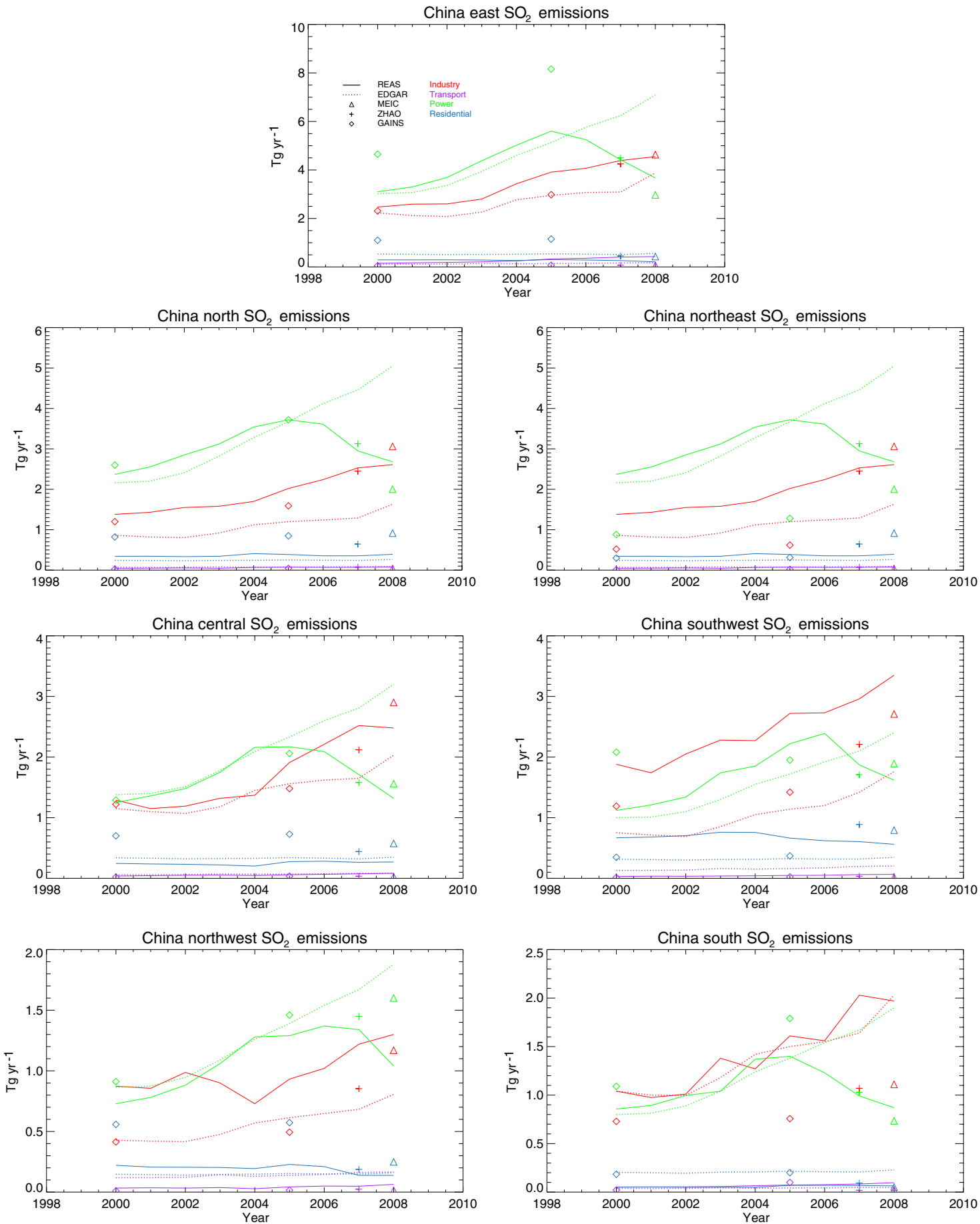

Figure 7. Regional total emissions for $\mathrm{SO}_{2}$ for four different source sectors (industry, transport, power, and residential) estimated by REAS, EDGAR, MEIC, ZHAO, and GAINS between 2000 and 2008.

sions, by 2008, industry is the largest source sector for CO in the two largest source regions - East and North - regardless of which inventory. REAS CO emissions estimates are consistently higher than those of EDGAR across all regions except for the Northeast for industry emissions, and MEIC, ZHAO, and GAINS CO emissions estimates for this sector generally fall between the estimates of REAS and EDGAR. The two regions where this does not apply are Central and Northwest, and their industrial $\mathrm{CO}$ emissions estimates by MEIC, ZHAO, and GAINS are higher than the estimates by the other two emissions inventories. Analysis at the source sector level reveals that the majority of the differences in $\mathrm{CO}$ 
emissions among the inventories stem from the industry sector and that they are, in many regions, increasing over time.

The second largest $\mathrm{CO}$ source is the residential sector, and the estimates by the national inventories MEIC and ZHAO are always higher in all regions than the regional inventory REAS and the global inventory EDGAR estimates. GAINS estimates the residential sector to be the largest source sector, and their estimates are also usually higher than REAS and EDGAR in almost all regions, except in the Southwest and the South in 2005, where the REAS and GAINS estimates are close to each other. EDGAR estimates for residential sector emissions are the lowest among the inventories analyzed here, because it does not include provincial but rather uses the national statistics-based IEA estimates for coal use in the residential sector, leading to lower activity level (Fig. 4). On the other hand, GAINS emissions for this sector are the highest because it is unique in considering factors which are technology specific, rather than using one factor per fuel for the whole residential sector. For example, there are significant differences in emissions for different types of stoves and boilers in the residential sector and these technology-specific data are incorporated into the GAINS model.

The third largest CO source and the source sector with the second largest difference after industry is transport, contributing $45.6 \%(34.4 \%)$ of the total difference in 2000 (2008). Emissions from the North and East regions contribute to these large differences. Both REAS and EDGAR emissions inventories show decrease at the national level, although, at the regional scale, the change is variable, ranging from $-0.59 \mathrm{Tg}(-1.5 \mathrm{Tg})$ for EDGAR to $-1.8 \mathrm{Tg}(1.4 \mathrm{Tg})$ for REAS between 2000 and 2008 in the North (East). This difference might be due to a couple of reasons. First, emission factors and reduction measures assumed can be different. For example, EDGAR may be estimating much larger emissions reduction in newer vehicles with more stringent emission standards. Second, the number of vehicles assumed in different vehicle types is different among the inventories (Fig. 10), even if the total number may be similar. For REAS, the number of vehicles of each type (passenger cars, buses, light and heavy-duty trucks, and motorcycles) in 2000 was taken from Borken et al. (2008) and extrapolated to 2008, using trends from the National Bureau of Statistics (20012009) (Kurokawa et al., 2013). Emission factors due to control strategies and policies in REAS stem from estimates in Borken et al. (2008) and Wu et al. (2011), as explained in Saikawa et al. (2011). For EDGAR, the fleet distribution is based on the international statistics from the International Road Federation (IRF, 1990, 2005, 2007) which were analyzed in the framework of the EU "Quantify" project (Borken et al., 2008). Zhang et al. (2009) estimated an $11 \%$ decrease in CO from the transport sector between 2001 and 2006 due to emissions control technologies, despite the doubling of the number of vehicles in the same period. We will analyze the transport emissions in more detail in Sect. 3.3 as we have some more disaggregated data for this sector available for comparison.

At the regional level, the ranking of source sectors does not always hold and also changes over time. For Northwest, emissions from the residential sector are estimated to be the largest in all years in all inventories. In Southwest, REAS estimates slightly higher industrial emissions $\left(6.6 \mathrm{Tg} \mathrm{yr}^{-1}\right.$ in 2000 and $12.4 \mathrm{Tg} \mathrm{yr}^{-1}$ in 2008) than residential emissions (6.3 $\mathrm{Tg} \mathrm{yr}^{-1}$ in 2000 and $9.9 \mathrm{Tg} \mathrm{yr}^{-1}$ in 2008), but EDGAR estimates higher transport emissions $\left(2.5 \mathrm{Tg} \mathrm{yr}^{-1}\right)$ than industrial $\left(2.0 \mathrm{Tg} \mathrm{yr}^{-1}\right)$ in 2000. Similarly, in the South, REAS estimates industry to be the largest source sector $\left(6.4 \mathrm{Tg} \mathrm{yr}^{-1}\right)$ followed by residential $\left(5.3 \mathrm{Tg} \mathrm{yr}^{-1}\right)$ and transport $\left(4.5 \mathrm{Tg} \mathrm{yr}^{-1}\right)$ in 2008, whereas EDGAR estimates residential to be the largest $\left(3.7 \mathrm{Tg} \mathrm{yr}^{-1}\right)$, followed by industry in a close second $\left(3.4 \mathrm{Tg} \mathrm{yr}^{-1}\right)$ and transport $\left(0.73 \mathrm{Tg} \mathrm{yr}^{-1}\right)$ with much lower emissions than the other two in the same year. This clearly illustrates the importance of constraining emissions at the disaggregated levels.

The East, encompassing the Pearl River Delta and the industrial coast, is the largest source region of CO. In 2008, 32, 27 , and $26 \%$ of the national total CO emissions from REAS, EDGAR, and MEIC estimates, respectively, were emitted from this region. Similarly, ZHAO (GAINS) estimates $30 \%$ (29\%) of the national total CO emissions is from the East in 2007 (2005). CO emissions from the industry sector in the East, in particular, show large differences, and the absolute difference more than doubles from 2000 to 2008. In 2008, there is a $22.4 \mathrm{Tg} \mathrm{yr}^{-1}$ difference in $\mathrm{CO}$ emissions within the industry sector between REAS and EDGAR, which constitutes a $64 \%$ difference between the two emissions estimates in the East in that year. This difference makes up $25 \%$ of the difference between the two national total $\mathrm{CO}$ emissions estimates. The difference between the REAS and EDGAR emissions estimates for the transport sector for this region is also increasing and is $10.1 \mathrm{Tg} \mathrm{yr}^{-1}$ in 2008 , equivalent to $29 \%$ of the regional total $\mathrm{CO}$ difference and $11 \%$ of the national $\mathrm{CO}$ difference. One thing to note about this region is that EDGAR CO estimates for the transport sector are decreasing over time, whereas those of REAS indicate the opposite.

The North is the second largest source region of $\mathrm{CO}$, and it contributes 21,14 , and $21 \%$ of the national total $\mathrm{CO}$ emissions for REAS, EDGAR, and MEIC estimates, respectively, in 2008. ZHAO (GAINS) estimates $18.5 \%$ (18.1\%) of the national total $\mathrm{CO}$ emissions come from this region in 2007 (2005). Combined with the East emissions, the two regions contribute $53,42,47,48$, and $47 \%$ of the emissions in REAS, EDGAR, MEIC, ZHAO, and GAINS, respectively, in 2008 for the former three, 2007 for ZHAO, and 2005 for GAINS. The pattern shown for East and North, the more developed regions in China, is similar, and the only difference is that EDGAR estimates larger residential emissions compared to transport emissions in the East, whereas the opposite is the case for the North in the early 2000s. 


\subsubsection{Sulfur dioxide, $\mathrm{SO}_{2}$}

$\mathrm{SO}_{2}$ leads to acid rain through sulfuric acid deposition, destroying buildings by corroding metals and deteriorating paint and stone. Furthermore, it harms aquatic and terrestrial ecosystems. $\mathrm{SO}_{2}$ is also a precursor of sulfate aerosols that scatter radiation, leading to direct cooling of the atmosphere. Sulfate aerosols also act as condensation nuclei, making clouds more reflective and prolonging the lifetime of clouds, enhancing the cooling impact (Haywood and Boucher, 2000; Ramanathan et al., 2001).

Figure 7 shows the seven regional $\mathrm{SO}_{2}$ emissions estimates for each source sector. For $\mathrm{SO}_{2}$ emissions, the power sector is the largest source sector in most years for both REAS and EDGAR, and 38-54\% (52-61\%) of national total $\mathrm{SO}_{2}$ emissions are from the power sector in REAS (EDGAR) between 2000 and 2008. Contrary to CO emissions, we find a large divergence between REAS and EDGAR power sector emissions estimates during 2000-2008 across all regions. While EDGAR $\mathrm{SO}_{2}$ power emissions estimates continue to increase over time, those of REAS peak in that time range, although the specific year is not uniform across the regions. Up to the peak in the REAS estimates, REAS and EDGAR follow similar trajectories. However, REAS $\mathrm{SO}_{2}$ emissions in the Central region and the Northwest start to decrease in 2004, in 2005 in the South, East, and North, and in 2006 in the Northeast and the Southwest.

The large difference in $\mathrm{SO}_{2}$ emissions from the power sector between REAS and EDGAR is due to the difference in the assumed timing of the installation of FGD in coal-fired power plants. Newly designed policy incentives and an increase in policy inspection have led to an increase in the installation of FGD in China, and the percentage of plants with FGD increased from 10 to $71 \%$ between 2006 and 2009 (Xu, 2011). The number of power plants is listed in Table 3 . While EDGAR assumed a delayed penetration of FGD (1\%), electrostatic precipitators $(6 \%)$ and flue-gas recirculation $(4 \%)$ leaving $90 \%$ of power plants still fully uncontrolled in 2008 , REAS estimated a more optimistic installation scenario, especially for large power plants and referred to Lu et al. (2011) in deciding implementation rates of FGD to power plants in China. For example in 2007, Lu et al. (2011) used the range of $51.4-95 \%$, with the mean of $73.2 \%$, based on the Chinese Ministry of Environmental Protection official data (2009) reporting of $\mathrm{SO}_{2}$ removal efficiency of FGD and applying the triangular distribution with the ideal removal efficiency of $95 \%$ (Zhao et al., 2011). This explains why REAS emissions estimates from the power sector are closer to the emissions estimates by MEIC, and those by Lu et al. (2011), as seen in Figs. 3 and 7. The largest emissions decrease from the power sector are seen in the East and North regions, where there were 250 and 206 power plants, respectively, reinforcing that this difference is due to the FGD implementation assumption in power plants.
Table 3. Number of power plants in each region within China.

\begin{tabular}{lr}
\hline Region & $\begin{array}{r}\text { Number of } \\
\text { coal power plants }\end{array}$ \\
\hline East & 250 \\
North & 206 \\
Central & 86 \\
South & 78 \\
Northeast & 76 \\
Southwest & 66 \\
Northwest & 43 \\
\hline Source: Carbon Monitoring for Action \\
(2017).
\end{tabular}

The second largest source sector for China's $\mathrm{SO}_{2}$ emissions is industry. Nationally, it contributes $13(53 \%), 17$ (33\%), $17(53 \%), 14(44 \%)$, and $9.3(27 \%) \mathrm{Tg} \mathrm{yr}^{-1}$ of total $\mathrm{SO}_{2}$ emissions in REAS, EDGAR, and MEIC for 2008, ZHAO for 2007, and GAINS for 2005, respectively. In some regions, such as the Northeast, there is very little difference among inventories. On the other hand, we see a much larger difference in the Southwest. While EDGAR estimates industry to be the second largest source sector in this region, constituting $31-37 \%$ of regional emissions, all other emissions inventories estimate industry to be the largest source sector in the region, constituting 46-60\% of the regional total. Similar to its estimates for $\mathrm{CO}$ emissions, REAS tends to estimate higher emissions from the industry sector in most of the regions.

$\mathrm{SO}_{2}$ emissions differences in the two other sectors remain relatively small and constant across all regions, with the residential sector emissions in the Southwest as the only exception. The residential sector emissions difference in the Southwest between EDGAR and REAS estimates have decreased from $354 \mathrm{Gg} \mathrm{yr}^{-1}$ in 2000 to $215 \mathrm{Gg} \mathrm{yr}^{-1}$ in 2008 .

\subsubsection{Nitrogen oxides, $\mathrm{NO}_{x}$}

$\mathrm{NO}_{x}$ plays an important role in the formation of tropospheric $\mathrm{O}_{3}$ and nitrate aerosols. The $\mathrm{NO}_{x}$ emissions trend in Asia, and especially in China, has been an important topic, due to the rapid changes that have been observed in the past two decades (Richter et al., 2005; Gu et al., 2014). Figure 8 shows the seven regional $\mathrm{NO}_{x}$ emissions estimated for each source sector.

The large differences among the emissions inventories stem from the transport sector in the East, North, South, and Northwest. For the transport sector, the East has an increasing difference over time, changing from $0.40 \mathrm{Tg} \mathrm{yr}^{-1}$ in 2000 to $1.3 \mathrm{Tg} \mathrm{yr}^{-1}$ in 2008 . While transport contributes $27-30 \%$ of the regional total emissions for REAS in the East, it only contributes 15-19\% for EDGAR. MEIC estimates the transport sector in the East to contribute $25 \%$ of the regional total $\mathrm{NO}_{x}$ emissions. In the North, South, and Northwest, the 

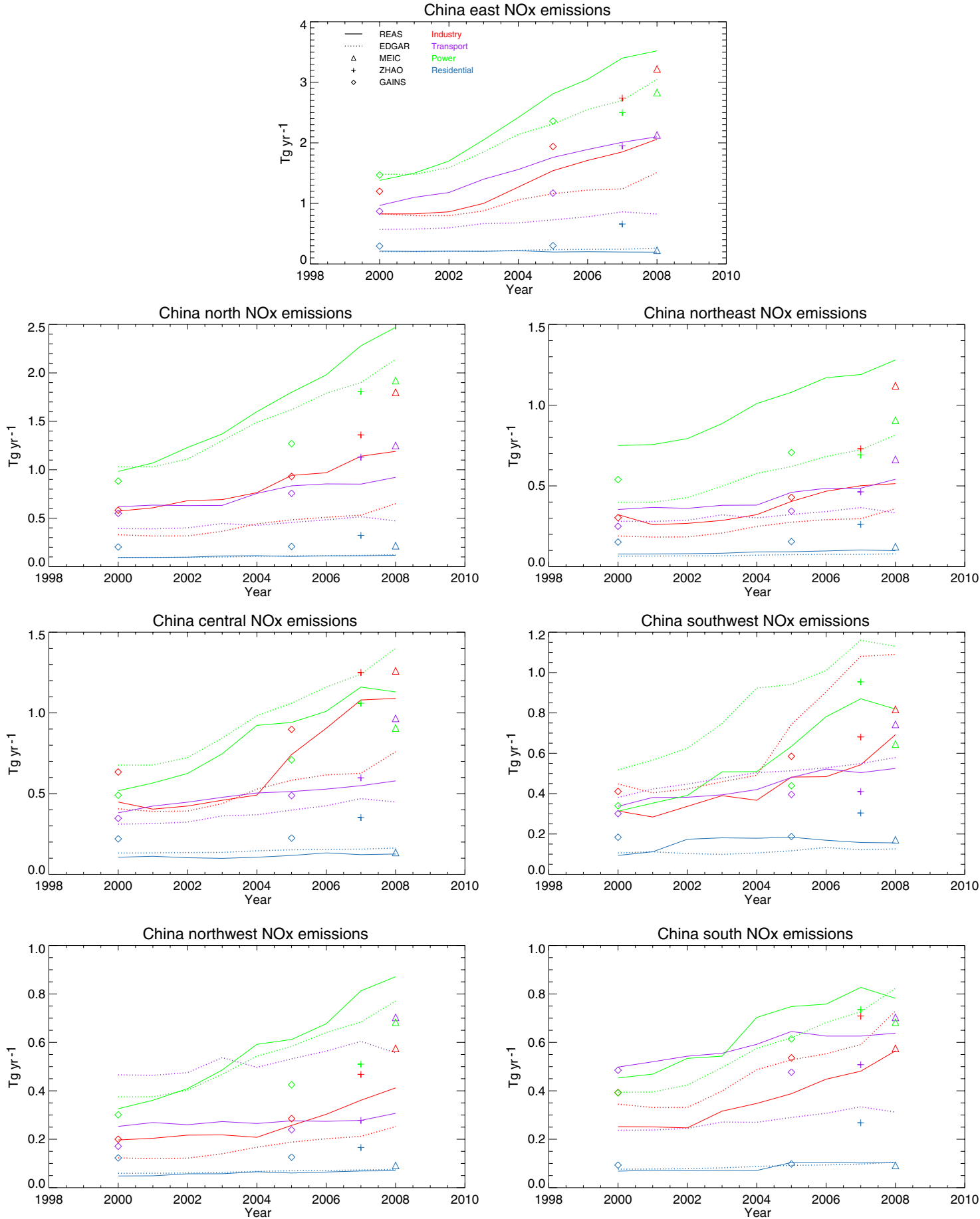

Figure 8. Regional total emissions for $\mathrm{NO}_{x}$ for four different source sectors (industry, transport, power, and residential) estimated by REAS, EDGAR, MEIC, ZHAO, and GAINS between 2000 and 2008.

difference in the transport sector emissions among the inventories can also be as high as 450,355 , and $326 \mathrm{Gg} \mathrm{yr}^{-1}$, respectively. The key reasons why the differences are large and why they are growing are 2-fold. First, as we explain later in Sect. 4, the differences in the allocation of fuel (gasoline and diesel) and the differences in vehicle categories play a role.
Second, the pace of the implementation of measures assumed among different inventories is different.

Little to no emissions control technologies for $\mathrm{NO}_{x}$ has been developed and promoted in China for the power and industrial combustion sectors, and this is the main reason why we see a large increase for $\mathrm{NO}_{x}$ emissions. China only 
used low- $\mathrm{NO}_{x}$ combustion technology and started to install selective reduction methods after 2005 (B. Zhao et al., 2013). The only other $\mathrm{NO}_{x}$ mitigation strategy for China was emissions standards for reducing tailpipe emissions from vehicles (B. Zhao et al., 2013). For example, there is no national $\mathrm{NO}_{x}$ emissions standard for coal-fired industrial boilers, as opposed to the vehicle emission standards that have been tightened over the years.

\subsubsection{Coarse particulate matter, $\mathbf{P M}_{10}$}

China's $\mathrm{PM}_{10}$ emissions have been increasing rapidly and they contribute approximately 21.6 (15.2) $\mathrm{Tg} \mathrm{yr}^{-1}$ of the 38.3 (39.3) $\mathrm{Tg} \mathrm{yr}^{-1}$ total $\mathrm{PM}_{10}$ emissions from 22 Asian countries, i.e., Afghanistan, Bangladesh, Bhutan, Nepal, Sri Lanka, India, Maldives, Pakistan, South Korea, North Korea, China, Japan, Singapore, Taiwan, Laos, Cambodia, Brunei, Myanmar, Philippines, Thailand, Vietnam, and Indonesia, in the REAS (EDGAR) estimate. These differences between REAS and EDGAR estimates indicate the large differences in China, as well as in other parts of Asia. Here, we only discuss primary emissions of $\mathrm{PM}_{10}$, emitted directly from anthropogenic sources.

Figure 9 shows the seven regional $\mathrm{PM}_{10}$ emissions estimates for each source sector. The largest source sector, as well as the largest emissions difference, stems from the industry sector. Industrial emissions contribute 64, 19, and $78 \%$ of the total $\mathrm{PM}_{10}$ emissions in REAS, EDGAR, and MEIC for 2008, respectively, and $65 \%(50 \%)$ for ZHAO (GAINS) for 2007 (2005). As illustrated in the low industrial contribution in 2008 in EDGAR, its industrial emissions increased by $1.3 \mathrm{Tg}$ from 2000 to 2008, while those of REAS increased by $5.8 \mathrm{Tg}$ in the same period. This large increase in industrial $\mathrm{PM}_{10}$ emissions is due to the fast growth of industry and limited stringency of air quality legislation and its poor enforcement (B. Zhao et al., 2013). In addition, uncertainty accounting for fugitive emissions due to leaks or other unintentional releases adds to the difference among the inventories. For industrial $\mathrm{PM}_{10}$ emissions, REAS estimates are always consistently higher than those of EDGAR in all regions, and the difference between the two inventories is 4 to 5-fold, constituting $61-74 \%$ of the total differences.

We see relatively little change in differences among the inventories between 2000 and 2008 for transport and residential sectors. It is also important to point out that the spatial distribution of emissions in some of the inventories, especially the global ones, are often more static than the national ones due to the limited local information, although this static nature over time of the global inventories is not only for $\mathrm{PM}_{10}$ but also applies to other species as well. There are, however, some interesting sector-dependent differences. First, GAINS estimates higher residential emissions than REAS and EDGAR in all regions in both 2000 and 2005 except in the South in 2005. Second, REAS estimates are not always higher than those of EDGAR for the residential sector emissions. In the Northeast, REAS $\mathrm{PM}_{10}$ emissions estimates are higher than those of EDGAR. For the Southwest and the North, REAS emissions estimates are higher than EDGAR estimates only for the period 2002-2005.

\section{Road transport sector comparison}

Rapid growth in the number of vehicles has created a significant air quality challenge in China. Many have researched the importance of on-road transport emissions on Beijing's (Hao et al., 2001; Westerdahl et al., 2009) and China's air quality (Fu et al., 2001; Walsh, 2007; Saikawa et al., 2011). We found significant differences in $\mathrm{CO}$ and $\mathrm{NO}_{x}$ emissions in the transport sector, and here we analyze the differences for these emissions in more depth by focusing on both on-road and off-road transport emissions. Here, we first compare the contribution of different vehicle categories to the total vehicles in REAS, EDGAR, and GAINS. Then, we compare on-road and off-road emissions estimates of $\mathrm{CO}, \mathrm{NO}_{x}, \mathrm{SO}_{2}$, and $\mathrm{PM}_{10}$ at the national level as well as for each region for $\mathrm{CO}$ and $\mathrm{NO}_{x}$.

Comparing the contribution of various gasoline (Fig. 10a) vehicles among the three inventories, EDGAR is very different from the other two. The similar comparison for diesel vehicles (Fig. 10b) reveals an even larger difference among inventories. As stated earlier for the industrial sector, it is likely that emission factors and/or the technology levels estimated within each of the vehicle types are causing the differences. EDGAR emission factors specifically for on-road vehicles are not available, but, comparing the net transport-sector emission factors between EDGAR and GAINS, GAINS has a 5.6 times higher value per unit of fuel than EDGAR. The lack of modeling super-emitters in EDGAR is also contributing significantly to the differences. It is also possible that something more fundamental, such as the definition of vehicle types, is causing the differences.

In the following section, we compare national on-road and off-road transport emissions first among REAS, EDGAR, ZHAO, and GAINS and then in the seven regions within China (East, North, Northeast, Central, Southwest, Northwest, and South, as shown in Fig. 1), for REAS, EDGAR, and ZHAO. We compare in detail the differences among emissions inventories for each species per region and for each source sector below.

\subsection{Carbon monoxide, $\mathrm{CO}$}

Figure 11 shows the national and seven regional $\mathrm{CO}$ transport emissions estimated in REAS, EDGAR, ZHAO, and GAINS (national estimate only), separated into on-road and off-road emissions. The figure clearly shows that the difference in this sector stems from on-road emissions. Additionally, $99 \%$ of the difference between REAS and EDGAR CO transport emissions is from on-road at the national level, and 

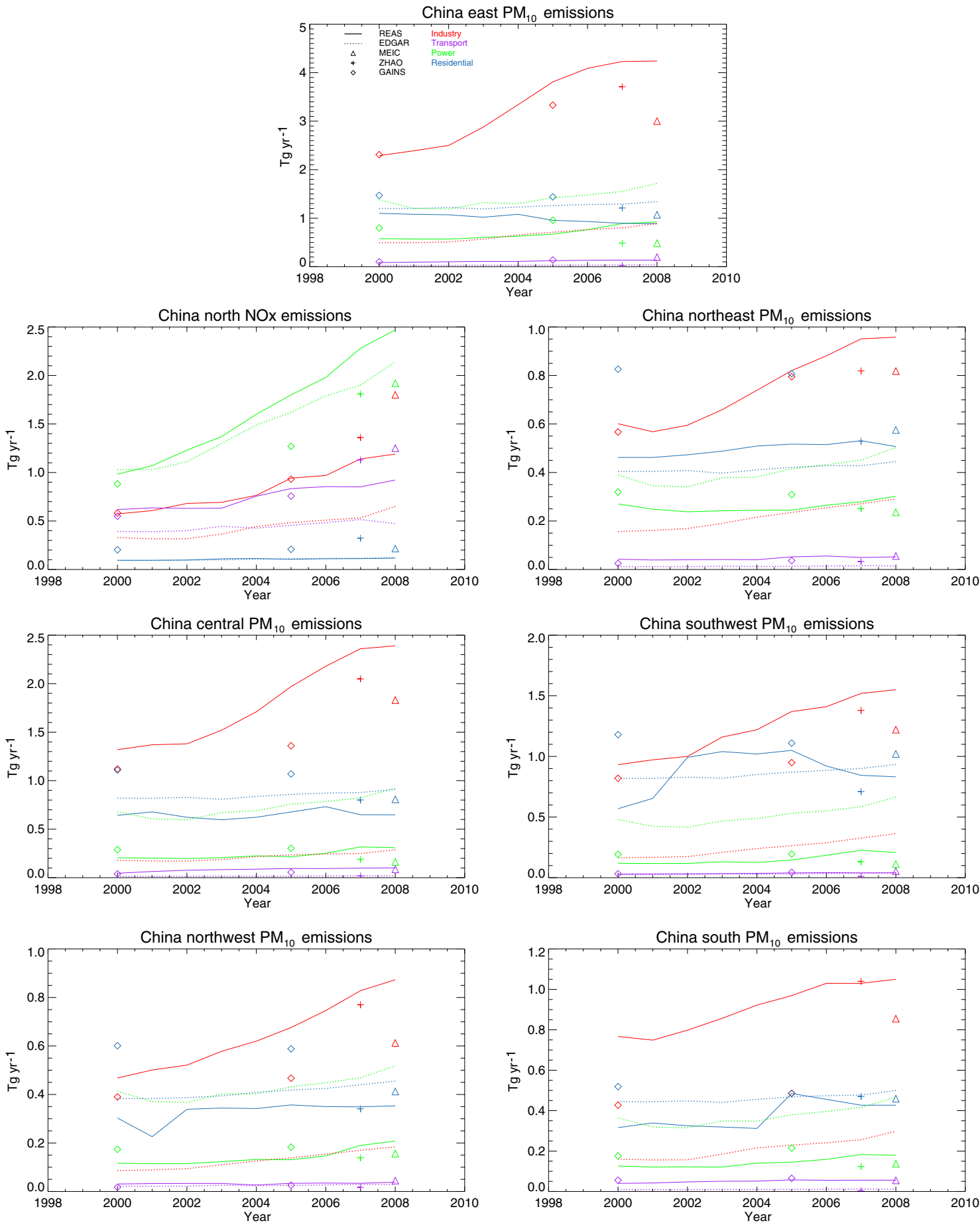

Figure 9. Regional total emissions for $\mathrm{PM}_{10}$ for four different source sectors (industry, transport, power, and residential) estimated by REAS, EDGAR, MEIC, ZHAO, and GAINS between 2000 and 2008.

in the East we see up to a difference of $99.4 \%$ at the regional level. Indeed, at the national and all regional levels, there is at least a 2-fold difference in emissions between REAS and EDGAR on-road emissions. ZHAO on-road emissions estimates are always in between REAS and EDGAR estimates, and ZHAO off-road estimates are always higher than both REAS and EDGAR. 
(a)

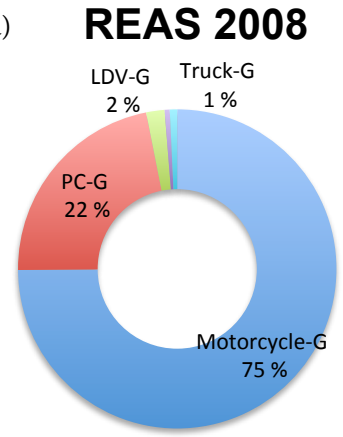

(b)

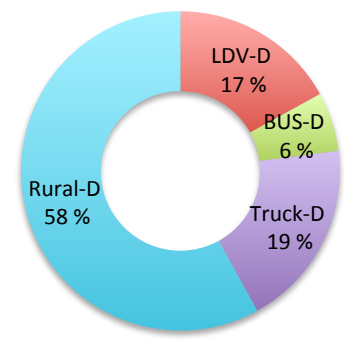

EDGAR 2008

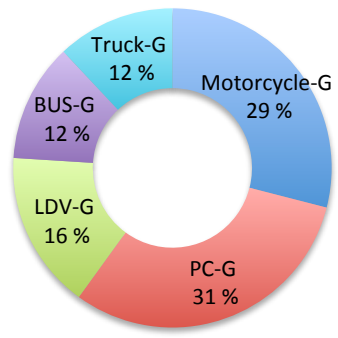

EDGAR 2008

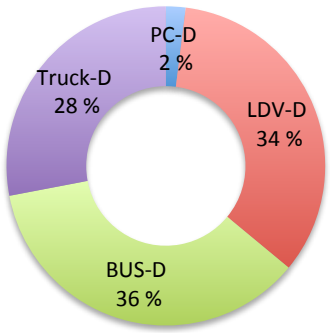

GAINS 2005

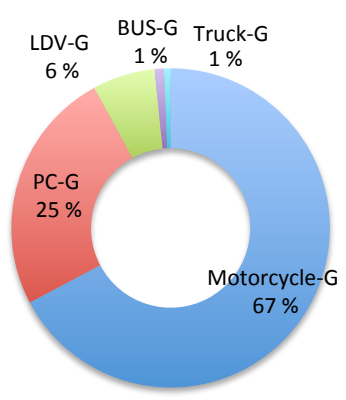

GAINS 2005

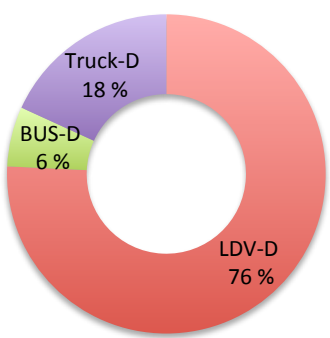

Figure 10. (a) Contribution of each of the vehicle categories to the number of gasoline vehicles. (b) Contribution of each of the vehicle categories to the number of diesel vehicles.

\subsection{Nitrogen oxides, $\mathrm{NO}_{x}$}

Figure 12 shows the national and seven regional $\mathrm{NO}_{x}$ transport emissions estimated in REAS, EDGAR, and ZHAO, separated into on-road and off-road emissions. Contrary to the $\mathrm{CO}$ emissions, there are many regional differences in these emissions estimates. At the national level, REAS (ZHAO) estimates 42-56\% (49\%) higher for on-road emissions compared to EDGAR. Off-road emissions are much more constrained among the three emissions inventories and REAS and EDGAR give similar estimates between 2005 and 2007.

The East is estimated to contribute 28-38, 6.3-6.8, and $37 \%$ of the total transport emissions in REAS, EDGAR, and ZHAO, respectively. REAS (ZHAO) emissions estimates are 5.6-7.4 (6.2) times larger than EDGAR on-road emissions and 2.6-9.5 (6.7) times larger than off-road emissions. For $\mathrm{NO}_{x}$ emissions, although on-road emissions are still larger in most of the regions, off-road emissions are also important and are mostly increasing in both REAS and EDGAR. For the East, REAS estimates an increase from $307 \mathrm{Gg} \mathrm{yr}^{-1}$ in 2000 to $1100 \mathrm{Gg} \mathrm{yr}^{-1}$ in 2008 in off-road emissions. For the Northwest, EDGAR estimates larger emissions from offroad compared to on-road for $\mathrm{NO}_{x}$, which we do not see in either REAS or ZHAO. REAS estimates a higher growth rate for off-road emissions and their emissions estimates increase from $28.4 \mathrm{Gg} \mathrm{yr}^{-1}$ in 2000 to $75.1 \mathrm{Gg} \mathrm{yr}^{-1}$ in 2008 , while EDGAR off-road emissions estimates only increase from $98.5 \mathrm{Gg} \mathrm{yr}^{-1}$ to $110 \mathrm{Gg} \mathrm{yr}^{-1}$ over the same time period. The large emissions differences in the region are most likely due to much greater railway emissions by coal and diesel locomotives assumed in the EDGAR inventory, compared to REAS.

\subsection{Coarse particulate matter $\mathbf{P M}_{10}$ and sulfur dioxide $\mathrm{SO}_{2}$}

Figure 13 shows the national $\mathrm{PM}_{10}$ and $\mathrm{SO}_{2}$ on-road and offroad emissions estimated in REAS, EDGAR, and GAINS. $\mathrm{PM}_{10}$ shows a good agreement for on-road emissions between REAS and GAINS, although EDGAR on-road is much lower. The low emissions estimates for EDGAR for $\mathrm{PM}_{10}$ is most likely due to the lack of super-emitters in EDGAR, since those are the primary emitters. On-road emissions for $\mathrm{SO}_{2}$ also shows a good agreement, especially between EDGAR and GAINS, although REAS values show an increase in the late 2000s that we do not find in the other two inventories. $\mathrm{SO}_{2}$ is calculated differently than for the other species in REAS, based on gasoline/diesel consumption instead of vehicle category. This might also be the reason for the difference among the inventories.

Off-road emissions are in especially good agreement for $\mathrm{PM}_{10}$ among the three inventories. However, they diverge quite significantly for $\mathrm{SO}_{2}$ emissions. GAINS, in particular, 

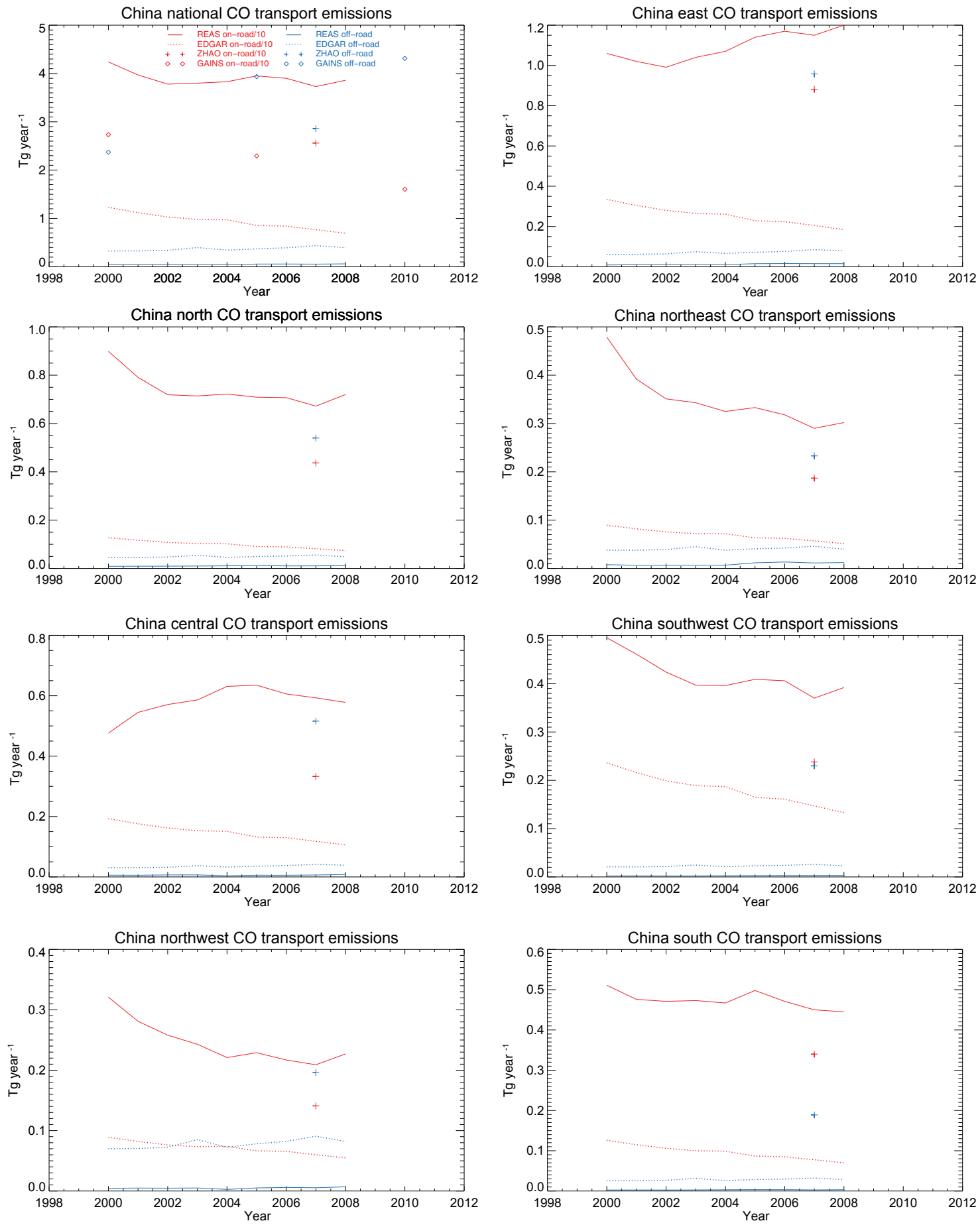

Figure 11. National and regional on-road and off-road transport sector emissions of CO estimated by REAS, EDGAR, ZHAO, and GAINS between 2000 and 2008 .

has low emissions estimates for off-road $\mathrm{SO}_{2}$ emissions, although it estimates high emissions for $\mathrm{CO}$ and $\mathrm{PM}_{10}$. It is most likely due to the high emission factors GAINS have for these off-road vehicles for $\mathrm{CO}$ and $\mathrm{PM}_{10}$ in the transport sector.

\section{Impacts on air quality}

\subsection{Model description}

To assess how these differences in emissions inputs affect air quality simulation results, we used the Weather Research 

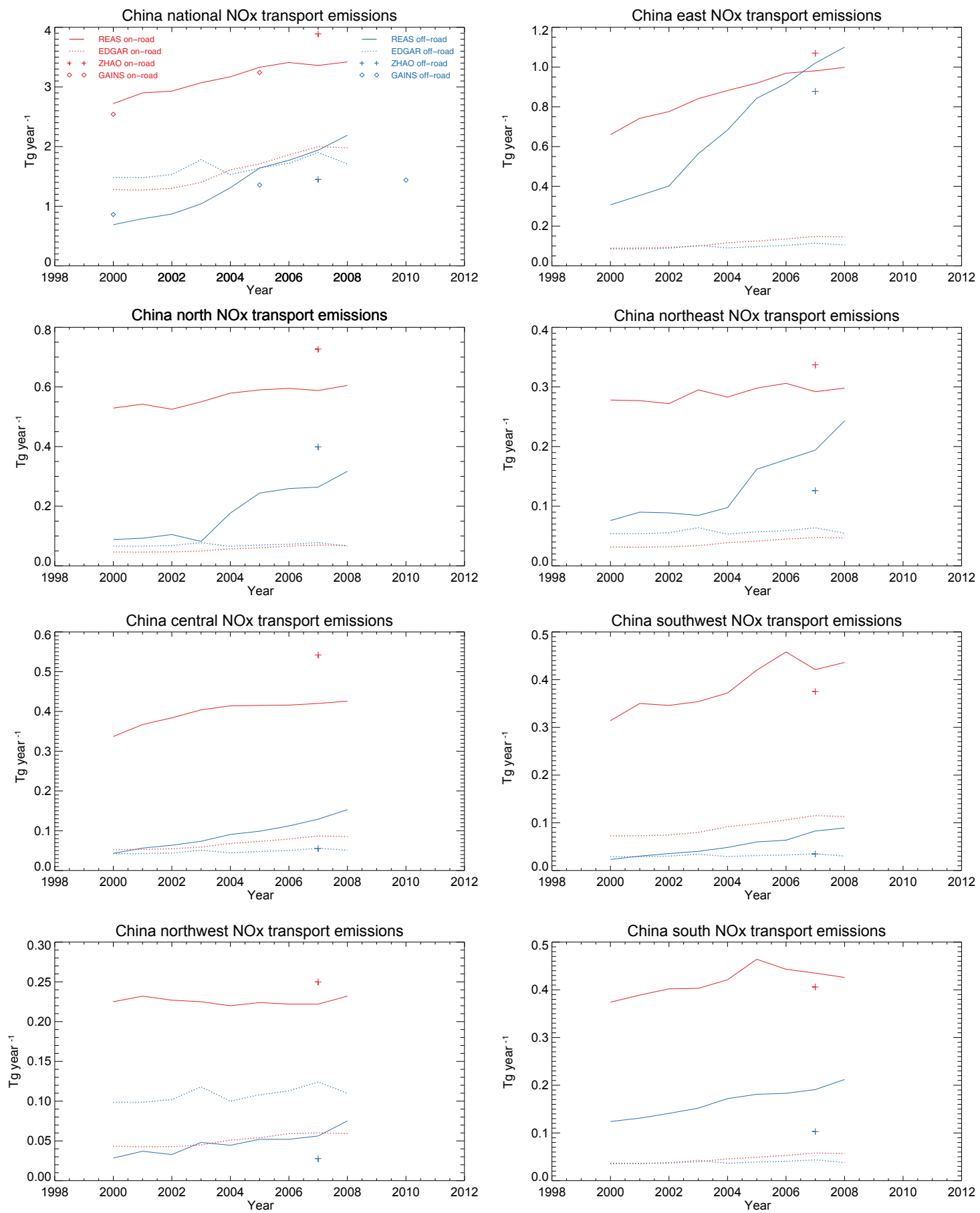

Figure 12. National and regional on-road and off-road transport sector emissions of $\mathrm{NO}_{x}$ estimated by REAS, EDGAR, ZHAO, and GAINS between 2000 and 2008 .

and Forecasting model coupled with Chemistry version 3.5 (Grell et al., 2005). The model domain covers much of the Asian region, with a horizontal resolution of $20 \times 20 \mathrm{~km}$ with 31 vertical levels and China at its center (Fig. 15). The initial and lateral chemical boundary conditions are taken from a present-day simulation of the NOAA Geophysical Fluid Dy- namics Laboratory (GFDL) global chemistry-climate model AM3 (Naik et al., 2013), driven by the global gridded emissions from the inventory of Lamarque et al. (2010). The meteorological data are obtained from the National Centers for Environmental Prediction (NCEP) Global Forecast System final gridded analysis datasets. We used Carbon bond mech- 

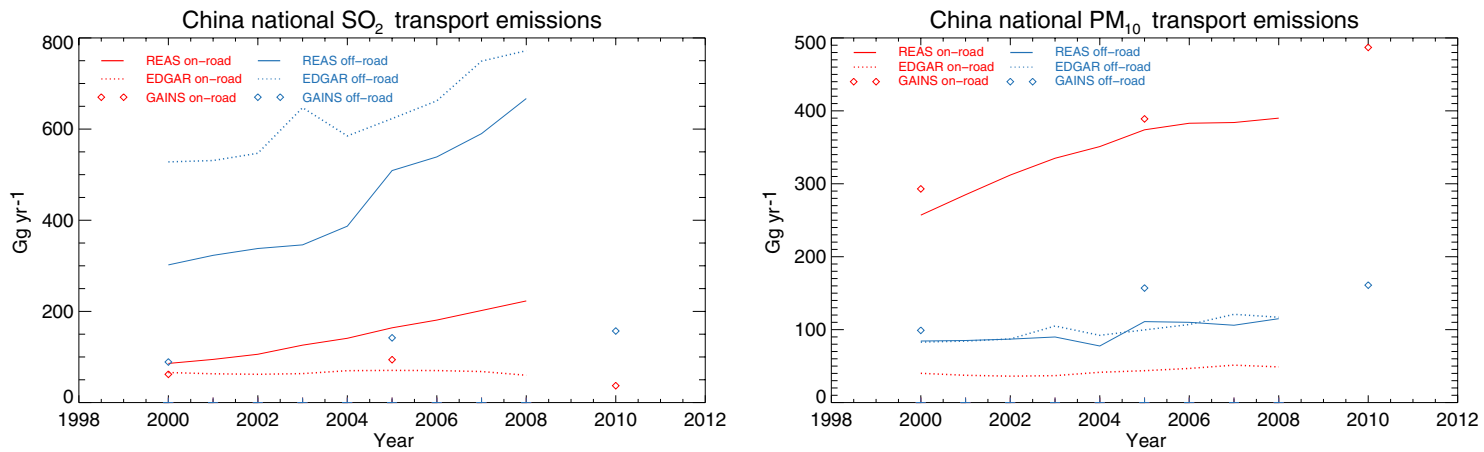

Figure 13. National on-road and off-road transport sector emissions of $\mathrm{SO}_{2}$ and $\mathrm{PM}_{10}$ estimated by REAS, EDGAR, and GAINS between 2000 and 2008.

anism version Z (CBMZ) (Zaveri and Peters, 1999) for gasphase chemistry and the Model for Simulating Aerosol Interactions and Chemistry (MOSAIC) (Zaveri et al., 2008) for aerosol chemistry. The rest of the model setup (aerosol dry deposition, wet deposition, photolysis, radiation, and microphysics) is the same as applied in our previous study (Zhong et al., 2016).

We chose the three emissions inventories that provided gridded emissions and are targeted at different scales: EDGAR at global, REAS at regional, and MEIC at national. In addition, EDGAR estimates the lowest emissions for most species, whereas REAS estimates the highest and thus provides a range of air quality simulations as a result of varying emissions. We then performed model simulations for January and July for 2008, using each of these inventories. Because MEIC only covers China, we applied REAS emissions outside of China for the simulation with MEIC. For biomass burning emissions, we used the Fire INventory from NCAR (FINN) (Wiedinmyer et al., 2011), and for biogenic emissions, we used the Model of Emissions of Gases and Aerosols from Nature (MEGAN) interactively within WRFChem (Guenther et al., 2012). For aircraft emissions, we used emissions developed for the Hemispheric Transport of Air Pollution (HTAP) for the year 2008 (Janssens-Maenhout et al., 2015). In order to focus on differences in air quality due to differing anthropogenic emissions estimates of gaseous pollutants and PM, we did not include dust simulation in this study. However, sea salt is calculated online (Gong, 2003). Before the beginning of each monthly simulation, the model was spun up for 10 days to ventilate the regional domain. The model simulation including dust has been validated with existing measurements for the year 2007 in Zhong et al. (2016), and here we focus on differences in air quality simulations due to differing gridded anthropogenic emissions inputs.

\subsection{Simulated results and discussion}

Figure 14a illustrates the spatial distribution of January emissions for $\mathrm{CO}, \mathrm{NO}_{x}, \mathrm{SO}_{2}, \mathrm{PM}_{10}$, and $\mathrm{NMVOC}$ that we used as inputs for the WRF-Chem simulations. As mentioned ear- lier, $\mathrm{CO}$ and $\mathrm{PM}_{10}$ show high variations, and the emissions are especially concentrated in the eastern part of China. Although national $\mathrm{SO}_{2}$ emissions appear highest in REAS estimates from Fig. 14; EDGAR estimates are the highest due to large point source emissions from power plants, as discussed earlier.

Figure 15a compares the simulated monthly mean $\mathrm{PM}_{10}$ concentrations, as well as that of $\mathrm{CO}, \mathrm{NO}_{2}, \mathrm{SO}_{2}$, and $\mathrm{O}_{3}$ mixing ratios in January 2008, using the three inventory estimates as emissions inputs. These differences in simulated concentrations or mixing ratios of pollutants are solely due to the emissions used as model inputs. Overall, the simulated monthly means show similar spatial distributions. All three simulations show high levels of $\mathrm{CO}, \mathrm{NO}_{2}, \mathrm{SO}_{2}$, and $\mathrm{PM}_{10}$ in the Beijing-Tianjin-Hebei area in the North, Shanxi province in the North, and Sichuan Basin in the Southwest. In contrast, the mixing ratios of $\mathrm{O}_{3}$ are relatively low over the same regions. Despite the similar spatial distributions, concentrations of the simulated monthly means differ substantially.

For CO, both simulations using REAS and MEIC result in higher mixing ratios than when using EDGAR. We quantified the regional monthly mean of each simulation by averaging all grid cells in each region, as illustrated in Table 4. The REAS and MEIC regional monthly means are 250-470 ppbv (269-294 ppbv) higher in the polluted area in the Central (the East) region than the EDGAR simulation. For $\mathrm{NO}_{2}$, the largest differences in regional monthly mean occur between simulations using EDGAR and MEIC emissions, mainly in the Central ( $8.1 \mathrm{ppbv})$ followed by the East (7.2 ppbv) and the Northeast (3.3 ppbv) region. These regions are where the differences in emissions are the largest as well. For $\mathrm{SO}_{2}$, both simulations using REAS and MEIC show differences in monthly mean less than $30 \%$ in most regions compared to those with EDGAR emissions, except in the Southwest, where REAS and MEIC estimates are 1.5 and 1.7 ppbv higher, respectively, than EDGAR estimates.

For $\mathrm{PM}_{10}$, EDGAR simulation is $20-60 \mu \mathrm{g} \mathrm{m}^{-3}$ lower than the other two in most regions. For example, MEIC simula- 

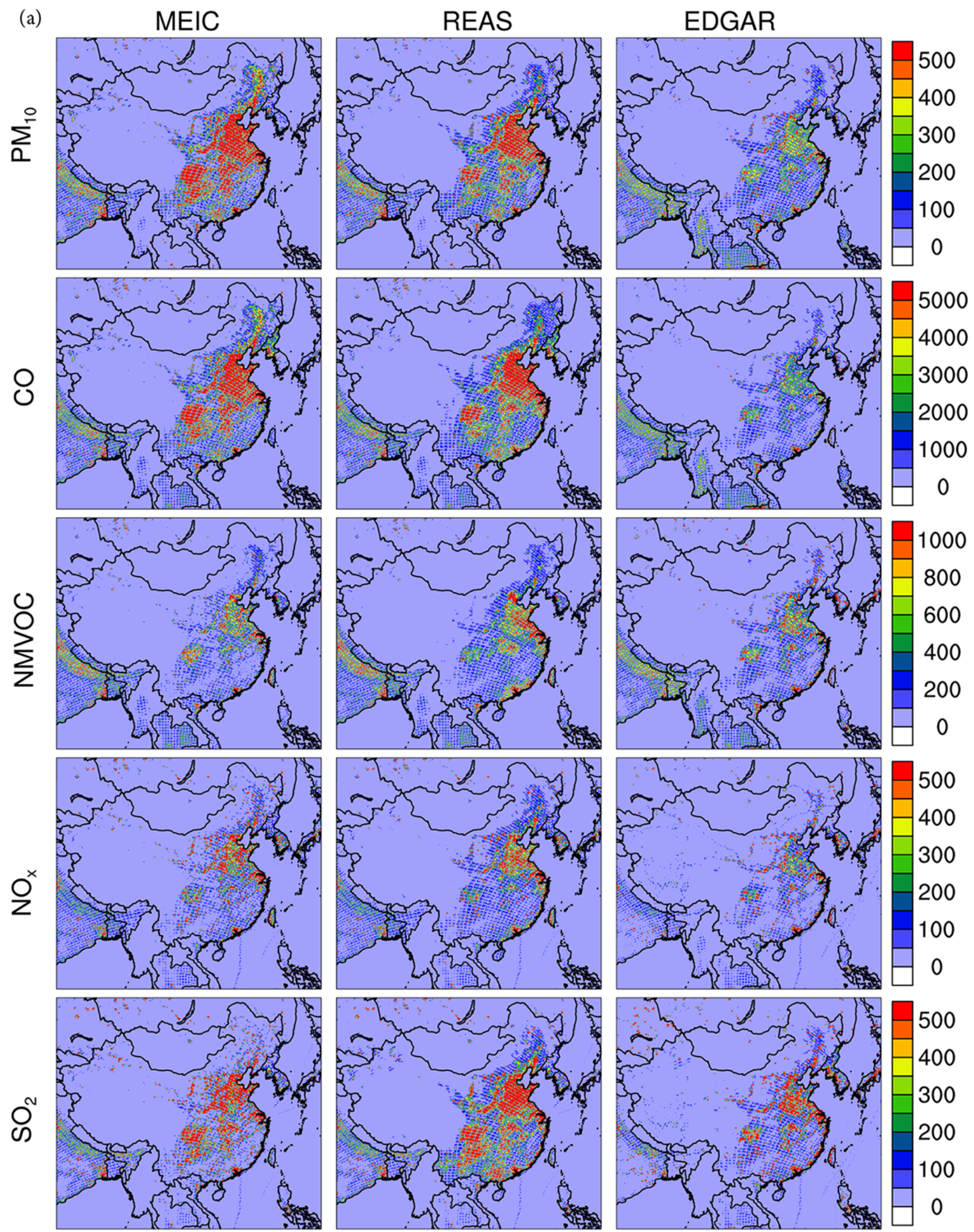

Figure 14. 
(b)
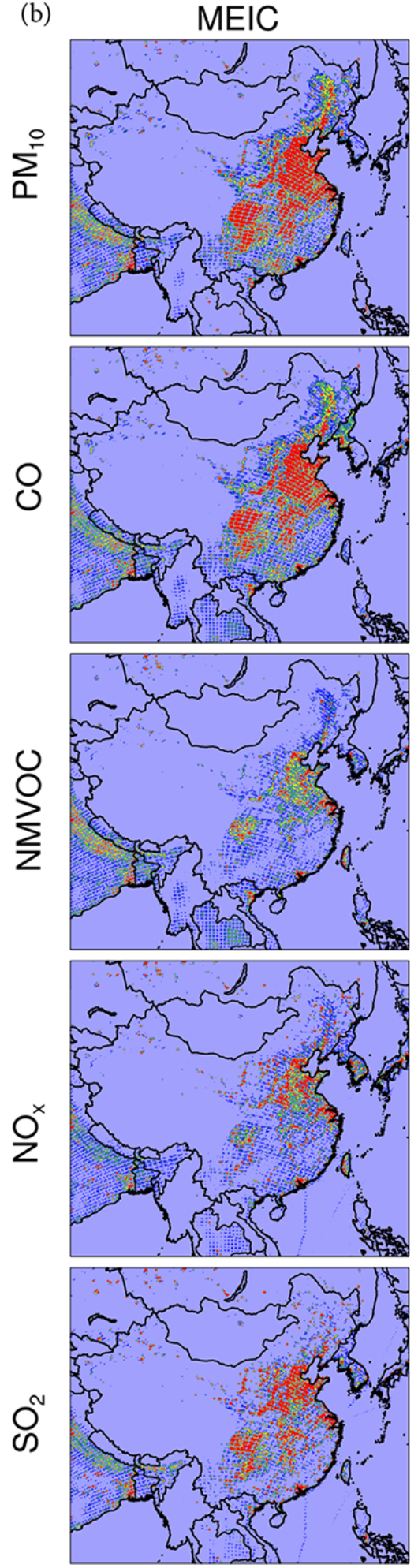
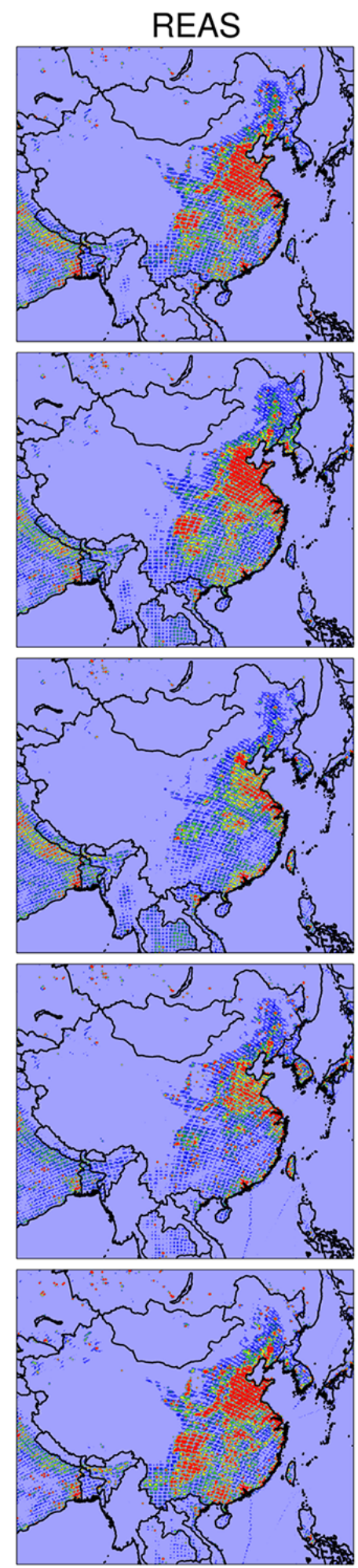
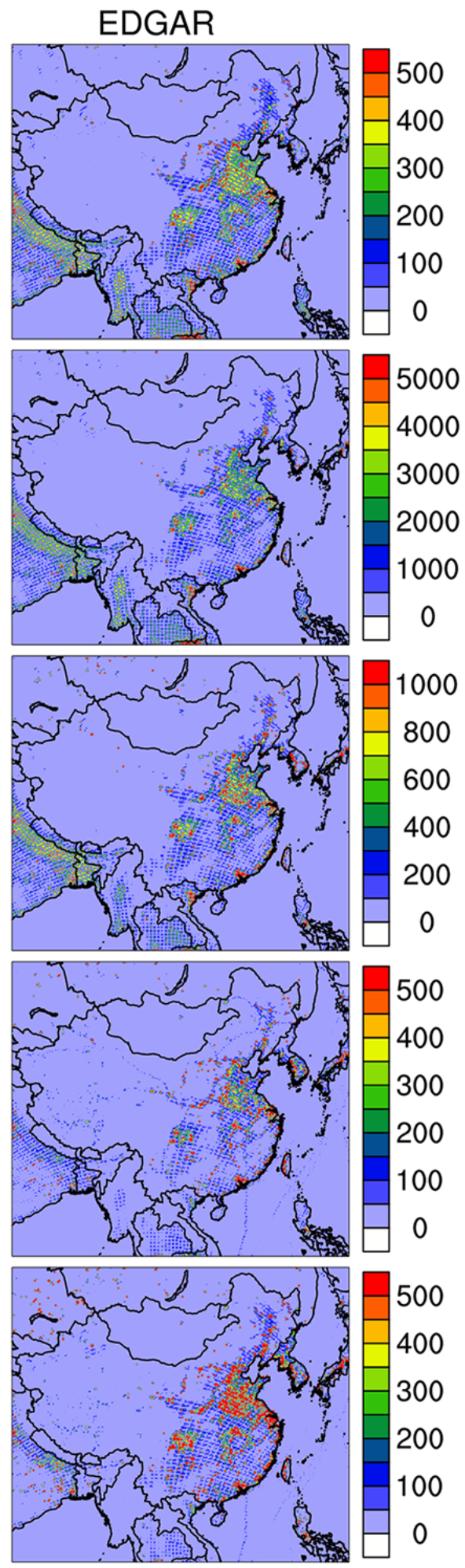

Figure 14. (a) Emissions of five pollutants $\left(\mathrm{PM}_{10}, \mathrm{CO}\right.$, NMVOC, $\mathrm{NO}_{x}$, and $\mathrm{SO}_{2}$ ) in $\mathrm{kg} \mathrm{km}^{-2}$ month ${ }^{-1}$ in January 2008 of the three emissions inventories. (b) Emissions of five pollutants $\left(\mathrm{PM}_{10}, \mathrm{CO}\right.$, NMVOC, $\mathrm{NO}_{x}$, and $\left.\mathrm{SO}_{2}\right)$ in $\mathrm{kg} \mathrm{km}^{-2}$ month ${ }^{-1}$ in July 2008 of the three emissions inventories. 

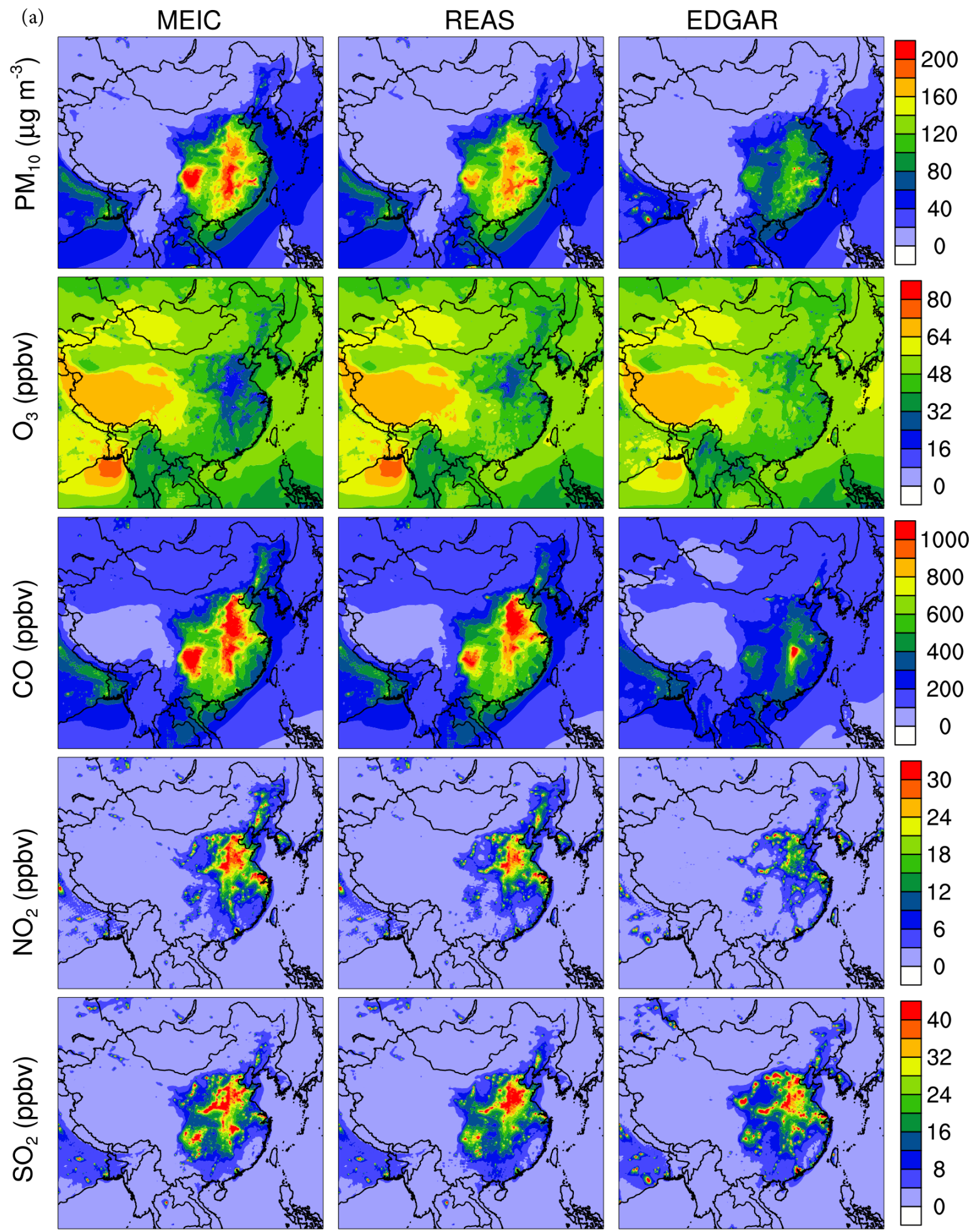

Figure 15. 

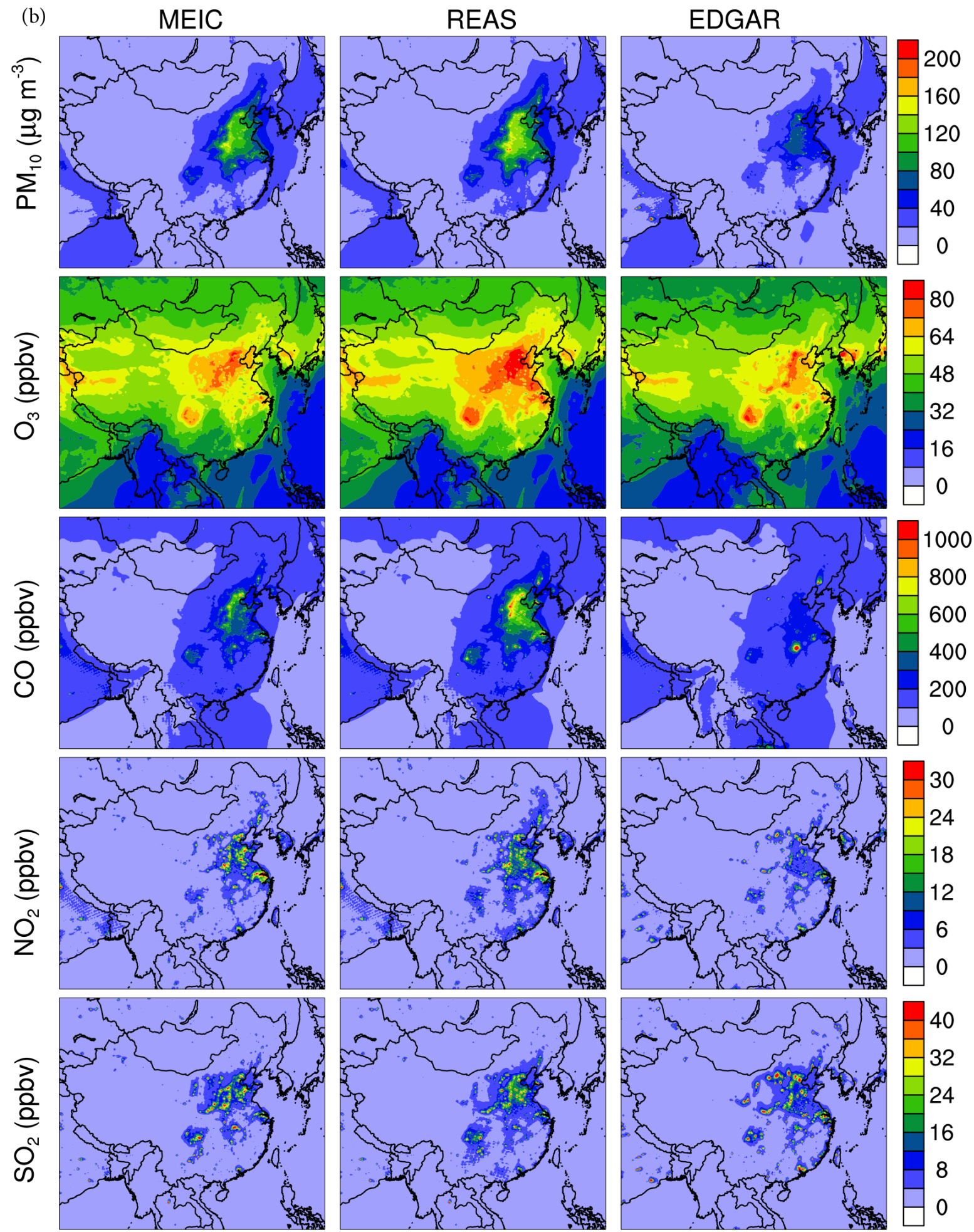

Figure 15. (a) Mixing ratios and concentrations of five pollutants in January using three emissions inventories. (b) Mixing ratios and concentrations of five pollutants in July using three emissions inventories. 

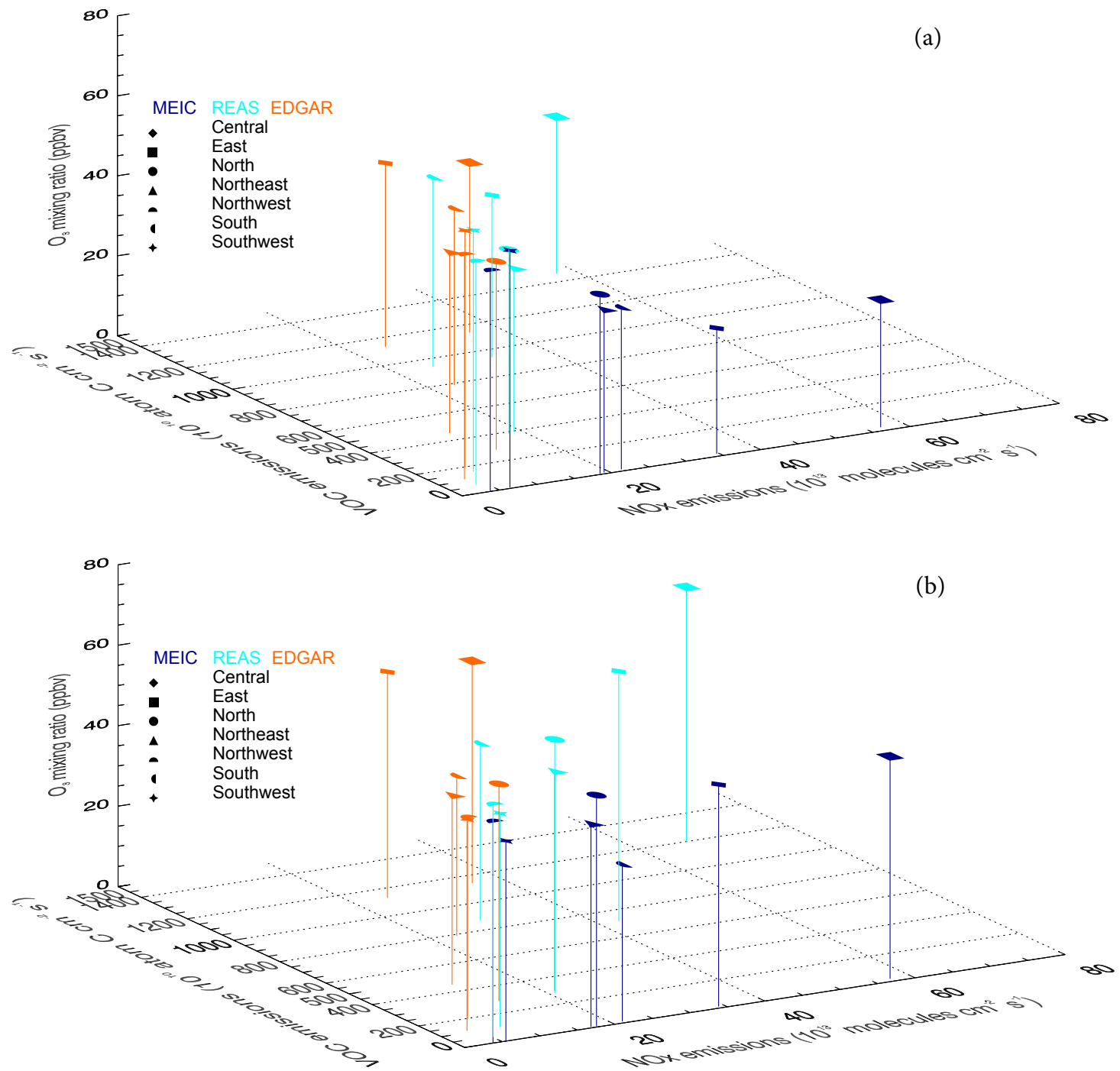

Figure 16. (a) Emissions of $\mathrm{NO}_{x}$ and VOCs as well as $\mathrm{O}_{3}$ mixing ratio in each region in January using three emissions inventories. (b) Emissions of $\mathrm{NO}_{x}$ and VOCs as well as $\mathrm{O}_{3}$ mixing ratio in each region in July using three emissions inventories.

tion estimates a $15 \mu \mathrm{g} \mathrm{m}^{-3}(103 \%)$ higher monthly mean in the Northeast and $19 \mu \mathrm{g} \mathrm{m}^{-3}$ (85\%) higher in the Southwest than EDGAR. REAS simulation estimates more than $55 \%$ higher monthly mean $\mathrm{PM}_{10}$ concentrations than EDGAR in most regions, with the highest difference $(76 \%)$ occurring in the Northeast. The largest absolute difference of $67 \mu \mathrm{g} \mathrm{m}^{-3}$ in a regional monthly mean between MEIC and EDGAR simulations is found in the Central region. Based on the observations from nine stations in Wuhan within the Central region, the monthly mean $\mathrm{PM}_{10}$ concentrations in January were $130 \mu \mathrm{g} \mathrm{m}^{-3}$ (Feng et al., 2011). This is closer to the simulated values using the MEIC (REAS) emissions inventory of 47.4 (50.6) $\mu \mathrm{g} \mathrm{m}^{-3}$, compared to the value using the EDGAR emissions inventory of $32.3 \mu \mathrm{g} \mathrm{m}^{-3}$, although the model simulations are largely underestimated due partially to the exclusion of dust.
For $\mathrm{O}_{3}$, simulations using REAS and EDGAR inputs show only a slight difference in monthly mean of $1-5$ ppbv in January. However, $\mathrm{O}_{3}$ mixing ratios using MEIC emissions are much lower than those using EDGAR emissions in the Central $(31 \%)$ and the East $(25 \%)$. MEIC's low anthropogenic VOC emissions in combination with high $\mathrm{NO}_{x}$ emissions in these regions (see Fig. 14) bring much higher $\mathrm{NO}_{x}$ titration and produce a VOC-limited environment, as illustrated in Fig. 16. For these two regions, despite the REAS and MEIC having similar $\mathrm{NO}_{x}$ emissions, their VOC emissions differ by more than 10 times. EDGAR emissions are the lowest for $\mathrm{NO}_{x}$ for both the Central and the East, but their estimates are the largest for VOCs in the Central and the second largest in the East among the three inventories. In both cases, simulations using EDGAR inventory lead to the largest $\mathrm{O}_{3}$ mixing ratios, due to the limited titration of $\mathrm{NO}_{x}$ during the night- 


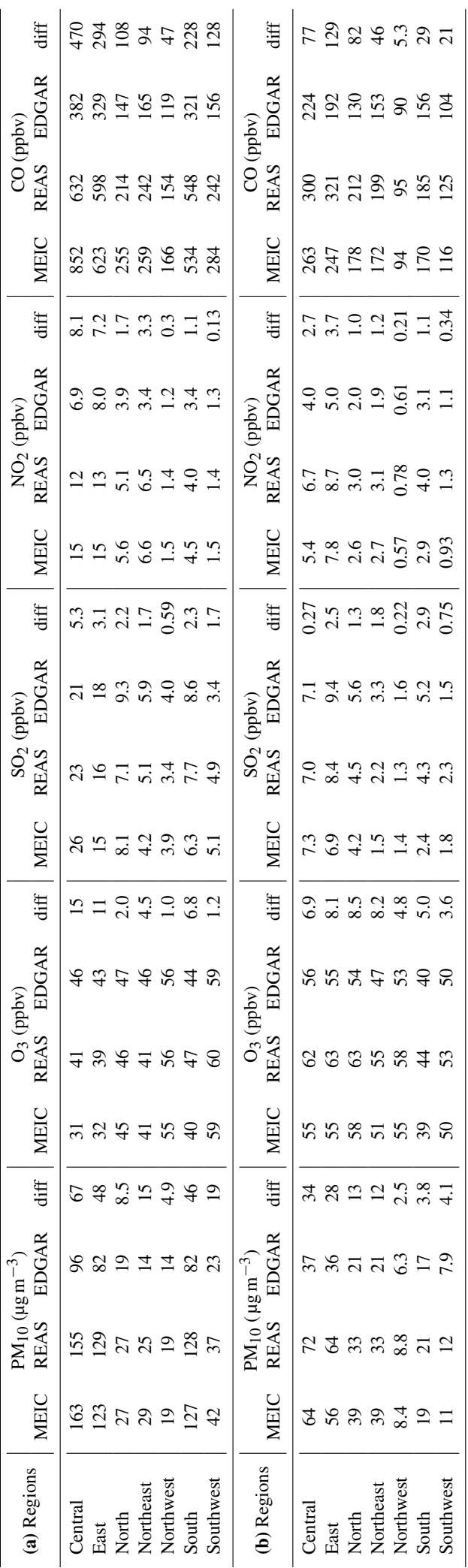

time. The $\mathrm{NO}_{x}$ mixing ratio in these two regions estimated in EDGAR is much lower compared to that in REAS and MEIC, as seen in Fig. 15. This result illustrates the importance of constraining $\mathrm{NO}_{x}$ and $\mathrm{VOC}$ emissions in the East and Central regions in understanding the way to mitigate $\mathrm{O}_{3}$ pollution for the future.

We also analyzed the differences of three simulations in July 2008 (Fig. 15b). We find a difference of more than $50 \%$ for $\mathrm{CO}, \mathrm{NO}_{2}, \mathrm{SO}_{2}$, and $\mathrm{PM}_{10}$ in one or more regions. The Central and the East again showed the largest differences, as found in January. There was a $34 \mu \mathrm{g} \mathrm{m}^{-3}$ difference in $\mathrm{PM}_{10}$ in Central China between REAS and EDGAR and a 129 ppbv difference in the East for CO between REAS and MEIC. Again, the Wuhan mean for July of $70 \mu \mathrm{g} \mathrm{m}^{-3}$ of $\mathrm{PM}_{10}$ was better captured by MEIC (REAS) of 52.0 (53.5) $\mu \mathrm{g} \mathrm{m}^{-3}$ compared to that by EDGAR of $36.0 \mu \mathrm{g} \mathrm{m}^{-3}$. The difference we find for $\mathrm{O}_{3}$ in East, North, and Central are also important, due to the high mixing ratio estimated in REAS being close to the $8 \mathrm{~h}$ WHO guideline of $100 \mu \mathrm{g} \mathrm{m}^{-3}$. From Fig. 16b, it is clear that the difference of $\mathrm{O}_{3}$ mixing ratio in these three regions is again due almost solely to the VOC emissions between REAS and MEIC.

\section{Conclusions}

In this study, we compared five emissions inventories of anthropogenic $\mathrm{CO}_{2}$ and air pollutant emissions in China at national and regional levels from four source sectors. The REAS and EDGAR inventories have been developed and maintained for years and have been extensively used for air quality modeling over the Asian continent, while the two national emissions inventories (MEIC and ZHAO) were recently developed, and few air quality modeling studies have been published using the data from these inventories at this time. GAINS has its roots in the Regional Air Pollution INformation and Simulation (RAINS)-Asia model dating back to early 1990 s project covering primarily $\mathrm{SO}_{2}$ and later on developed to include more pollutants. The GAINS dataset used here originates from a global project and has been used in several air quality and climate modeling exercises. This analysis reveals large differences in emissions estimates among the existing inventories. Furthermore, analysis of regional and sector specific emissions, as opposed to total national emissions, reveals differences in emissions from certain sectors that would not have been noticed by only analyzing the national total emissions.

We find that there is a significant need to better constrain emissions at the source sector and regional levels. Transparency in what inputs are used to create different emissions inventories is critical for a more thorough comparison. $\mathrm{CO}$ emissions differ the most, and those from the transport sector, especially the on-road transport emissions, need to be better constrained. Industrial emissions also tend to have a large difference among inventories, and $\mathrm{SO}_{2}$ emissions from the 
power sector also need to be assessed, especially for recent years. The East and the North are the two largest emitting regions, and more efforts are needed to understand emissions from these areas.

Emissions inputs have a large impact on air quality simulation results in China nationally and more prominently within the regions. Different emissions inputs lead to a $67 \mu \mathrm{g} \mathrm{m}{ }^{-3}$ $\left(34 \mu \mathrm{g} \mathrm{m}^{-3}\right)$ monthly mean difference in $\mathrm{PM}_{10}$ concentrations in Central China in January (July). Similarly, we found a 470 ppbv difference in January in Central and 129 ppbv difference in July in the East for CO. We also found that all the three inventory emissions estimates create a VOClimited environment in the Central region and the East. It is most prominent in MEIC estimates and its emissions produce much lower $\mathrm{O}_{3}$ mixing ratio estimates, compared to the simulations using REAS and EDGAR estimates in January. The difference in emissions inputs leads to a $15 \mathrm{ppbv}$ difference in $\mathrm{O}_{3}$ in Central China in January. In July, we find an $8.5 \mathrm{ppbv}$ difference in North, where REAS simulations lead to a monthly mean of $63 \mathrm{ppbv} \mathrm{O}_{3}$. Our results illustrate that a better understanding of Chinese emissions at more disaggregated levels is essential for finding effective mitigation measures for reducing national and regional air pollution in China.

Data availability. Monthly average model simulation results are available upon request to the authors. Other data sources are provided in the paper.

Competing interests. The authors declare that they have no conflict of interest.

Acknowledgements. We thank the editor and the two anonymous reviewers for constructive comments that improved the manuscript. We also thank Geoffrey Martin and Raquel Soat for their assistance in this project. The project was partly supported by the National Science Foundation (grant number AGS-1350021). REAS is supported by the Global Environmental Research Fund of the Ministry of the Environment Japan (S-7 and S-12). The NCEP GFS data used for this study are from the Research Data Archive (RDA), which is maintained by the Computational and Information Systems Laboratory (CISL) at the National Center for Atmospheric Research (NCAR). The data are available at http://rda.ucar.edu/datasets/ds083.2/. We would like to acknowledge high-performance computing support from Yellowstone (ark:/85065/d7wd3xhc) provided by NCAR's Computational and Information Systems Laboratory, sponsored by the National Science Foundation.

Edited by: G. Frost

Reviewed by: two anonymous referees

\section{References}

Allred, E. N., Bleecker, E. R., Chaitman, B. R., Dahms, T. E., Gottlieb, S. O., Hackney, J. D., Pagano, M., Selvester, R. H., Walden, S. M., and Warren, J.: Short-Term Effects of Carbon Monoxide Exposure on the Exercise Performance of Subjects with Coronary Artery Disease, New Engl. J. Med., 321, 14261432, doi:10.1056/NEJM198911233212102, 1989.

Amann, M., Bertok, I., Borken, J., Chambers, A., Cofala, J., Dentener, F., Heyes, C., Kejun, J., Klimont, Z., Makowski, M., Matur, R., Purohit, P., Rafaj, P., Sandler, R., Schopp, W., Wagner, F., and Winiwarter, W.: GAINS-Asia. A tool to combat air pollution and climate change simultaneously, Tech. rep., International Institute for Applied Systems Analysis (IIASA), 2008.

Amann, M., Bertok, I., Borken-Kleefeld, J., Cofala, J., Heyes, C., Hoglund-Isaksson, L., Klimont, Z., Nguyen, B., Posch, M., Rafaj, P., Sandler, R., Schopp, W., Wagner, F., and Winiwarter, W.: Cost-effective control of air quality and greenhouse gases in Europe: modeling and policy applications, Environ. Model. Softw., 26, doi:10.1016/j.envsoft.2011.07.012, 2011.

Andres, R. J., Boden, T. A., and Higdon, D.: A new evaluation of the uncertainty associated with CDIAC estimates of fossil fuel carbon dioxide emission, Tellus B, 66, 23616, doi:10.3402/tellusb.v66.23616, 2014.

Aronow, W. S. and Isbell, M. W.: Carbon Monoxide Effect on Exercise-Induced Angina Pectoris, Ann. Intern. Med., 79, 392395, doi:10.7326/0003-4819-79-3-392, 1973.

Avnery, S., Mauzerall, D. L., Liu, J., and Horowitz, L. W.: Global crop yield reductions due to surface ozone exposure: 1. Year 2000 crop production losses and economic damage, Atmos. Environ., 45, 2284-2296, doi:10.1016/j.atmosenv.2010.11.045, 2011.

Borken, J., Bei, X., Jiang, Y., and Meretei, T.: Road transportation in China: How big are fuel consumption and pollutant emissions really?, in: 87th Annual Meeting Transportation Research Board Abstract, Washington, DC, 2008.

Carbon Monitoring for Action: available at: http://www.carma.org/, last access: 28 April 2017.

Cui, H., Mao, P., Zhao, Y., Nielsen, C. P., and Zhang, J.: Patterns in atmospheric carbonaceous aerosols in China: emission estimates and observed concentrations, Atmos. Chem. Phys., 15, 86578678, doi:10.5194/acp-15-8657-2015, 2015.

Dockery, D. W., Pope, C. A., Xu, X., Spengler, J. D., Ware, J. H., Fay, M. E., Ferris, B. G., and Speizer, F. E.: An Association between Air Pollution and Mortality in Six US Cities, N. Engl. J. Med., 329, 1753-1759, 1993.

European Commission Joint Research Centre, JRC/Netherlands Environmental Assessment Agency (PBL): Emission Database for Global Atmospheric Research (EDGAR), release version 4.2., available at: http://edgar.jrc.ec.europa.eu (last access: 28 April 2017), 2011.

European Environment Agency: EMEP/EEA air pollutant emission inventory guidebook 2013, available at: http://www.eea. europa.eu/publications/emep-eea-guidebook-2013 (last access: 28 April 2017), 2013.

Feng, Q., Wu, S., Du, Y., Li, X., Ling, F., Xue, H., and Cai, S.: Variations of $\mathrm{PM}_{10}$ concentrations in Wuhan, China, Environ. Monit. Assess., 176, 259-271, doi:10.1007/s10661-010-1581-6, 2011. 
Fiore, A. M., Dentener, F. J., Wild, O., Cuvelier, C., Schultz, M. G., Hess, P., Textor, C., Schulz, M., Doherty, R. M., Horowitz, L. W., MacKenzie, I. A., Sanderson, M. G., Shindell, D. T., Stevenson, D. S., Szopa, S., Van Dingenen, R., Zeng, G., Atherton, C., Bergmann, D., Bey, I., Carmichael, G., Collins, W. J., Duncan, B. N., Faluvegi, G., Folberth, G., Gauss, M., Gong, S., Hauglustaine, D., Holloway, T., Isaksen, I. S. A., Jacob, D. J., Jonson, J. E., Kaminski, J. W., Keating, T. J., Lupu, A., Marmer, E., Montanaro, V., Park, R. J., Pitari, G., Pringle, K. J., Pyle, J. A., Schroeder, S., Vivanco, M. G., Wind, P., Wojcik, G., Wu, S., and Zuber, A.: Multimodel estimates of intercontinental sourcereceptor relationships for ozone pollution, J. Geophys. Res.Atmos., 114, d04301, doi:10.1029/2008JD010816, 2009.

Fu, L., Hao, J., He, D., He, K., and Li, P.: Assessment of vehicular pollution in China, J. Air Waste Manage., 51, 658-668, 2001.

GEA: Global Energy Assessment - Toward a Sustainable Future, Cambridge University Press, Cambridge UK and New York, NY, USA and the International Institute for Applied Systems Analysis, Laxenburg, Austria, 2012.

Gong, S. L.: A parameterization of sea-salt aerosol source function for sub- and super-micron particles, Global Biogeochem. Cy., 17, 1097, doi:10.1029/2003GB002079, 2003.

Granier, C., Bessagnet, B., Bond, T., D’Angiola, A., Denier van der Gon, H., Frost, G., Heil, A., Kaiser, J., Kinne, S., Klimont, Z., Kloster, S., Lamarque, J.-F., Liousse, C., Masui, T., Meleux, F., Mieville, A., Ohara, T., Raut, J.-C., Riahi, K., Schultz, M., Smith, S., Thompson, A., van Aardenne, J., van der Werf, G., and van Vuuren, D.: Evolution of anthropogenic and biomass burning emissions of air pollutants at global and regional scales during the 1980-2010 period, Climatic Change, 109, 163-190, doi:10.1007/s10584-011-0154-1, 2011.

Grell, G. A., Peckham, S. E., Schmitz, R., McKeen, S. A., Frost, G., Skamarock, W. C., and Eder, B.: Fully coupled "online" chemistry within the WRF model, Atmos. Environ., 39, 6957-6975, doi:10.1016/j.atmosenv.2005.04.027, 2005.

Gu, D., Wang, Y., Smeltzer, C., and Boersma, K. F.: Anthropogenic emissions of NOx over China: Reconciling the difference of inverse modeling results using GOME-2 and OMI measurements, J. Geophys. Res.-Atmos., 119, 7732-7740, doi:10.1002/2014JD021644, 2014.

Guenther, A. B., Jiang, X., Heald, C. L., Sakulyanontvittaya, T., Duhl, T., Emmons, L. K., and Wang, X.: The Model of Emissions of Gases and Aerosols from Nature version 2.1 (MEGAN2.1): an extended and updated framework for modeling biogenic emissions, Geosci. Model Dev., 5, 1471-1492, doi:10.5194/gmd-51471-2012, 2012.

Hao, J., Wu, Y., Fu, L., He, D., and He, K.: Source contributions to ambient concentrations of $\mathrm{CO}$ and $\mathrm{NO}_{x}$ in the urban area of Beijing, J. Environ. Sci. Health, A36, 215-228, 2001.

Haywood, J. and Boucher, O.: Estimates of the direct and indirect radiative forcing due to tropospheric aerosols: A review, Rev. Geophys., 38, 513-543, doi:10.1029/1999RG000078, 2000.

Heck, W. W., Adams, R. M., Cure, W. W., Heagle, A. S., Heggestad, H. E., Kohut, R. J., Kress, L. W., Rawlings, J. O., and Taylor, O. C.: A reassessment of crop loss from ozone, Environ. Sci. Technol., 17, 572A-581A, doi:10.1021/es00118a716, 1983.

Hsu, A., Emerson, J., Levy, M., de Sherbinin, A., Johnson, L., Malik, O., Schwartz, J., and Jaiteh, M.: The 2014 Environmental
Performance Index, Tech. rep., Yale Center for Environmental Law and Policy, New Haven, CT, 2014.

Janssens-Maenhout, G., Pagliari, V., and Muntean, M.: Global emission inventories in the Emission Database for Global Atmospheric Research (EDGAR) - Manual (I): Gridding: EDGAR emissions distribution on global grid maps, Tech. Rep. 25785, JRC, 2013.

Janssens-Maenhout, G., Crippa, M., Guizzardi, D., Dentener, F., Muntean, M., Pouliot, G., Keating, T., Zhang, Q., Kurokawa, J., Wankmüller, R., Denier van der Gon, H., Kuenen, J. J. P., Klimont, Z., Frost, G., Darras, S., Koffi, B., and Li, M.: HTAP_v2.2: a mosaic of regional and global emission grid maps for 2008 and 2010 to study hemispheric transport of air pollution, Atmos. Chem. Phys., 15, 11411-11432, doi:10.5194/acp15-11411-2015, 2015.

Klimont, Z., Cofala, J., Xing, J., Wei, W., Zhang, C., Wang, S., Kejun, J., Bhandari, P., Mathur, R., Purohit, P., Rafaj, P., Chambers, A., Amann, M., and Hao, J.: Projections of $\mathrm{SO}_{2}, \mathrm{NO}_{x}$ and carbonaceous aerosols emissions in Asia, Tellus B, 61, 602-617, doi:10.1111/j.1600-0889.2009.00428.x, 2009.

Klimont, Z., Smith, S. J., and Cofala, J.: The last decade of global anthropogenic sulfur dioxide: 2000-2011 emissions, Environ. Res. Lett., 8, 014003, doi:10.1088/1748-9326/8/1/014003 2013.

Klimont, Z., Kupiainen, K., Heyes, C., Purohit, P., Cofala, J., Rafaj, P., Borken-Kleefeld, J., and Schöpp, W.: Global anthropogenic emissions of particulate matter including black carbon, Atmos. Chem. Phys. Discuss., doi:10.5194/acp-2016-880, in review, 2016.

Krupa, S. V. and Manning, W. J.: Toxic Substance in the Environment Atmospheric ozone: Formation and effects on vegetation, Environ. Pollut., 50, 101-137, doi:10.1016/02697491(88)90187-X, 1988.

Kurokawa, J., Ohara, T., Morikawa, T., Hanayama, S., JanssensMaenhout, G., Fukui, T., Kawashima, K., and Akimoto, H.: Emissions of air pollutants and greenhouse gases over Asian regions during 2000-2008: Regional Emission inventory in ASia (REAS) version 2, Atmos. Chem. Phys., 13, 11019-11058, doi:10.5194/acp-13-11019-2013, 2013.

Lamarque, J.-F., Bond, T. C., Eyring, V., Granier, C., Heil, A., Klimont, Z., Lee, D., Liousse, C., Mieville, A., Owen, B., Schultz, M. G., Shindell, D., Smith, S. J., Stehfest, E., Van Aardenne, J., Cooper, O. R., Kainuma, M., Mahowald, N., McConnell, J. R., Naik, V., Riahi, K., and van Vuuren, D. P.: Historical (1850-2000) gridded anthropogenic and biomass burning emissions of reactive gases and aerosols: methodology and application, Atmos. Chem. Phys., 10, 7017-7039, doi:10.5194/acp10-7017-2010, 2010.

Lei, Y., Zhang, Q., He, K. B., and Streets, D. G.: Primary anthropogenic aerosol emission trends for China, 1990-2005, Atmos. Chem. Phys., 11, 931-954, doi:10.5194/acp-11-931-2011, 2011.

Levy, J. I., Carrothers, T. J., Tuomisto, J. T., Hammitt, J. K., and Evans, J. S.: Assessing the public health benefits of reduced ozone concentrations, Environ. Health Persp., 109, 1215-1226, 2001.

Levy, J. I., Chemerynski, S. M., and Sarnat, J. A.: Ozone Exposure and Mortality: "An Empiric Bayes Metaregression Analysis", Epidemiology, 16, 458-468, 2005.

Li, M., Zhang, Q., Streets, D. G., He, K. B., Cheng, Y. F., Emmons, L. K., Huo, H., Kang, S. C., Lu, Z., Shao, M., Su, H., Yu, X., 
and Zhang, Y.: Mapping Asian anthropogenic emissions of nonmethane volatile organic compounds to multiple chemical mechanisms, Atmos. Chem. Phys., 14, 5617-5638, doi:10.5194/acp14-5617-2014, 2014.

Li, M., Zhang, Q., Kurokawa, J.-I., Woo, J.-H., He, K., Lu, Z., Ohara, T., Song, Y., Streets, D. G., Carmichael, G. R., Cheng, Y., Hong, C., Huo, H., Jiang, X., Kang, S., Liu, F., Su, H., and Zheng, B.: MIX: a mosaic Asian anthropogenic emission inventory under the international collaboration framework of the MICS-Asia and HTAP, Atmos. Chem. Phys., 17, 935-963, doi:10.5194/acp17-935-2017, 2017.

Liu, F., Zhang, Q., Tong, D., Zheng, B., Li, M., Huo, H., and He, K. B.: High-resolution inventory of technologies, activities, and emissions of coal-fired power plants in China from 1990 to 2010, Atmos. Chem. Phys., 15, 13299-13317, doi:10.5194/acp15-13299-2015, 2015.

Lu, Z., Streets, D. G., Zhang, Q., Wang, S., Carmichael, G. R., Cheng, Y. F., Wei, C., Chin, M., Diehl, T., and Tan, Q.: Sulfur dioxide emissions in China and sulfur trends in East Asia since 2000, Atmos. Chem. Phys., 10, 6311-6331, doi:10.5194/acp-106311-2010, 2010.

Lu, Z., Zhang, Q., and Streets, D. G.: Sulfur dioxide and primary carbonaceous aerosol emissions in China and India, 1996-2010, Atmos. Chem. Phys., 11, 9839-9864, doi:10.5194/acp-11-98392011, 2011.

Morris, R. D., Naumova, E. N., and Munasinghe, R. L.: Ambient air pollution and hospitalization for congestive heart failure among elderly people in seven large US cities, Am. J. Public Health, 85, 1361-1365, 1995.

Mudway, I. and Kelly, F.: Ozone and the lung: a sensitive issue, Mol. Aspects Med., 21, 1-48, doi:10.1016/S0098-2997(00)00003-0, 2000.

Naik, V., Horowitz, L. W., Fiore, A. M., Ginoux, P., Mao, J., Aghedo, A. M., and Levy, H.: Impact of preindustrial to presentday changes in short-lived pollutant emissions on atmospheric composition and climate forcing, J. Geophys. Res.-Atmos., 118, 8086-8110, doi:10.1002/jgrd.50608, 2013.

National Bureau of Statistics: China statistical yearbook (2000 2008), China Statistics Press, 2001-2009.

Ohara, T., Akimoto, H., Kurokawa, J., Horii, N., Yamaji, K., Yan, X., and Hayasaka, T.: An Asian emission inventory of anthropogenic emission sources for the period 1980-2020, Atmos. Chem. Phys., 7, 4419-4444, doi:10.5194/acp-7-4419-2007, 2007.

Olivier, J. G. J., Berdowski, J. J. M., Peters, J. A. H. W., Bakker, J., Visschedijk, A. J. H., and Bloos, J. P. J.: Including a description of EDGAR 3.2: reference database with trend data for 19701995, RIVM report 773301 001, RIVM, Bilthoven, 2001.

Pope III, C. A., Burnett, R. T., thun, M. J., Calle, E. E., Krewski, D., Ito, K., and Thurston, G. D.: Lung cancer, cardiopulmonary mortality, and long-term exposure to fine particulate air pollution, J. Am. Med. Assoc., 287, 1132-1141, 2002.

Ramanathan, V., Crutzen, P. J., Kiehl, J. T., and Rosenfeld, D.: Aerosols, Climate, and the Hydrological Cycle, Science, 294, 2119-2124, doi:10.1126/science.1064034, 2001.

Richter, A., Burrows, J. P., Nusz, H., Granier, C., and Niemeier, U.: Increase in tropospheric nitrogen dioxide over China observed from space, Nature, 437, 129-132, doi:10.1038/nature04092, 2005.
Saikawa, E., Kurokawa, J., Takigawa, M., Borken-Kleefeld, J., Mauzerall, D. L., Horowitz, L. W., and Ohara, T.: The impact of China's vehicle emissions on regional air quality in 2000 and 2020: a scenario analysis, Atmos. Chem. Phys., 11, 9465-9484, doi:10.5194/acp-11-9465-2011, 2011.

Schwartz, J., Dockery, D. W., Neas, L. M., Wypij, D., Ware, J. H., Spengler, J. D., Koutrakis, P., Speizer, F. E., and Ferris, B. G.: Acute effects of summer air pollution on respiratory symptom reporting in children, Am. J. Resp. Crit. Care, 150, 1234-1242, doi:10.1164/ajrccm.150.5.7952546, 1994.

Smith, S. J., van Aardenne, J., Klimont, Z., Andres, R. J., Volke, A., and Delgado Arias, S.: Anthropogenic sulfur dioxide emissions: 1850-2005, Atmos. Chem. Phys., 11, 1101-1116, doi:10.5194/acp-11-1101-2011, 2011.

State Environmental Protection Administration (SEPA): Report on the State of the Environment in China, Beijing, 2000.

Stern, F. B., Halperin, W. E., Hornung, R. W., Ringenburg, V. L., and McCammon, C. S.: Heart disease mortality among bridge and tunnel officers exposed to carbon monoxide, Am. J. Epidemiol., 128, 1276-1288, 1988.

Streets, D. and Waldhoff, S.: Present and future emissions of air pollutants in China: $\mathrm{SO}_{2}, \mathrm{NO}_{x}$, and $\mathrm{CO}$, Atmos. Environ., 34, 363-374, doi:10.1016/S1352-2310(99)00167-3, 2000.

Streets, D. G., Bond, T. C., Carmichael, G. R., Fernandes, S. D., Fu, Q., He, D., Klimont, Z., Nelson, S. M., Tsai, N. Y., Wang, M. Q., Woo, J.-H., and Yarber, K. F.: An inventory of gaseous and primary aerosol emissions in Asia in the year 2000, J. Geophys. Res.-Atmos., 108, 8809, doi:10.1029/2002JD003093, 2003.

Streets, D. G., Zhang, Q., Wang, L., He, K., Hao, J., Wu, Y., Tang, Y., and Carmichael, G. R.: Revisiting China's CO emissions after the Transport and Chemical Evolution over the Pacific (TRACE-P) mission: Synthesis of inventories, atmospheric modeling, and observations, J. Geophys. Res.-Atmos., 111, d14306, doi:10.1029/2006JD007118, 2006.

Walsh, M. P.: Can China control the side effects of motor vehicle growth?, Nat. Resour. Forum, 31, 21-34, doi:10.1111/j.14778947.2007.00136.x, 2007.

West, J. J., Naik, V., Horowitz, L. W., and Fiore, A. M.: Effect of regional precursor emission controls on long-range ozone transport - Part 2: Steady-state changes in ozone air quality and impacts on human mortality, Atmos. Chem. Phys., 9, 6095-6107, doi:10.5194/acp-9-6095-2009, 2009.

Westerdahl, D., Wang, X., Pan, X., and Zhang, K. M.: Characterization of on-road vehicle emission factors and microenvironmental air quality in Beijing, China, Atmos. Environ., 43, 697-705, doi:10.1016/j.atmosenv.2008.09.042, 2009.

Wiedinmyer, C., Akagi, S. K., Yokelson, R. J., Emmons, L. K., AlSaadi, J. A., Orlando, J. J., and Soja, A. J.: The Fire INventory from NCAR (FINN): a high resolution global model to estimate the emissions from open burning, Geosci. Model Dev., 4, 625641, doi:10.5194/gmd-4-625-2011, 2011.

Wu, Y., Wang, R., Zhou, Y., Lin, B., Fu, L., He, K., and Hao, J.: On-Road Vehicle Emission Control in Beijing: Past, Present, and Future, Environ. Sci. Technol., 45, 147-153, doi:10.1021/es1014289, 2011.

Xia, Y., Zhao, Y., and Nielsen, C. P.: Benefits of China's efforts in gaseous pollutant control indicated by the bottom-up emissions and satellite observations 2000-2014, Atmos. Environ., 136, 43 53, doi:10.1016/j.atmosenv.2016.04.013, 2016. 
$\mathrm{Xu}, \mathrm{Y}$.: Improvements in the Operation of $\mathrm{SO}_{2}$ Scrubbers in China's Coal Power Plants, Environ. Sci. Technol., 45, 380-385, doi:10.1021/es1025678, 2011.

Zaveri, R. A. and Peters, L. K.: A new lumped structure photochemical mechanism for large-scale applications, J. Geophys. Res.Atmos., 104, 30387-30415, doi:10.1029/1999JD900876, 1999.

Zaveri, R. A., Easter, R. C., Fast, J. D., and Peters, L. K.: Model for Simulating Aerosol Interactions and Chemistry (MOSAIC), J. Geophys. Res.-Atmos., 113, D13204, doi:10.1029/2007JD008782, 2008.

Zhang, Q., Streets, D. G., Carmichael, G. R., He, K. B., Huo, H., Kannari, A., Klimont, Z., Park, I. S., Reddy, S., Fu, J. S., Chen, D., Duan, L., Lei, Y., Wang, L. T., and Yao, Z. L.: Asian emissions in 2006 for the NASA INTEX-B mission, Atmos. Chem. Phys., 9, 5131-5153, doi:10.5194/acp-9-5131-2009, 2009.

Zhang, Q., He, K., and Huo, H.: Policy, Cleaning China's Air, Nature, 484, 161-162, 2012.

Zhao, B., Wang, S. X., Liu, H., Xu, J. Y., Fu, K., Klimont, Z., Hao, J. M., He, K. B., Cofala, J., and Amann, M.: NOx emissions in China: historical trends and future perspectives, Atmos. Chem. Phys., 13, 9869-9897, doi:10.5194/acp-13-9869-2013, 2013.

Zhao, Y., Wang, S., Duan, L., Lei, Y., Cao, P., and Hao, J.: Primary air pollutant emissions of coal-fired power plants in China: Current status and future prediction, Atmos. Environ.t, 42, 84428452, doi:10.1016/j.atmosenv.2008.08.021, 2008.

Zhao, Y., Nielsen, C. P., Lei, Y., McElroy, M. B., and Hao, J.: Quantifying the uncertainties of a bottom-up emission inventory of anthropogenic atmospheric pollutants in China, Atmos. Chem. Phys., 11, 2295-2308, doi:10.5194/acp-11-2295-2011, 2011.
Zhao, Y., Nielsen, C. P., McElroy, M. B., Zhang, L., and Zhang, $\mathrm{J}$.: $\mathrm{CO}$ emissions in China: Uncertainties and implications of improved energy efficiency and emission control, Atmos. Environ., 49, 103-113, doi:10.1016/j.atmosenv.2011.12.015, 2012.

Zhao, Y., Zhang, J., and Nielsen, C. P.: The effects of recent control policies on trends in emissions of anthropogenic atmospheric pollutants and $\mathrm{CO}_{2}$ in China, Atmos. Chem. Phys., 13, 487-508, doi:10.5194/acp-13-487-2013, 2013.

Zhao, Y., Zhang, J., and Nielsen, C. P.: The effects of energy paths and emission controls and standards on future trends in China's emissions of primary air pollutants, Atmos. Chem. Phys., 14, 8849-8868, doi:10.5194/acp-14-8849-2014, 2014.

Zhao, Y., Zhong, H., Zhang, J., and Nielsen, C. P.: Evaluating the effects of China's pollution controls on inter-annual trends and uncertainties of atmospheric mercury emissions, Atmos. Chem. Phys., 15, 4317-4337, doi:10.5194/acp-15-4317-2015, 2015.

Zheng, B., Huo, H., Zhang, Q., Yao, Z. L., Wang, X. T., Yang, X. F., Liu, H., and He, K. B.: High-resolution mapping of vehicle emissions in China in 2008, Atmos. Chem. Phys., 14, 9787-9805, doi:10.5194/acp-14-9787-2014, 2014.

Zhong, M., Saikawa, E., Liu, Y., Naik, V., Horowitz, L. W., Takigawa, M., Zhao, Y., Lin, N.-H., and Stone, E. A.: Air quality modeling with WRF-Chem v3.5 in East Asia: sensitivity to emissions and evaluation of simulated air quality, Geosci. Model Dev., 9, 1201-1218, doi:10.5194/gmd-9-1201-2016, 2016. 